\title{
Palladium-Catalyzed Cascade \\ Cyclization/Dearomatization/Arylation of Alkyne- \\ Containing Phenol-Based Biaryls with Aryl Halides: An Entry to Diversely Functionalized Spirocyclohexadienones
}

\author{
Yunlong Bai, ${ }^{\dagger}$ Anjia Liu,${ }^{\dagger}$ Xin-Xing Wu, ${ }^{\dagger}$ Shufeng Chen, ${ }^{\dagger *}$ Jianbo Wang ${ }^{\ddagger *}$ \\ Inner Mongolia Key Laboratory of Fine Organic Synthesis, Department of Chemistry and \\ Chemical Engineering, Inner Mongolia University, Hohhot 010021, China \\ Beijing National Laboratory of Molecular Sciences (BNLMS), Key Laboratory of Bioorganic \\ Chemistry and Molecular Engineering of Ministry of Education, College of Chemistry, Peking \\ University, Beijing 100871, China. \\ E-mail:shufengchen@imu.edu.cn;wangjb@pku.edu.cn
}

Contents

1. ${ }^{1} \mathrm{H},{ }^{13} \mathrm{C}$ and ${ }^{19} \mathrm{~F}$ NMR spectra (3a-z) ..S2

2. ${ }^{1} \mathrm{H},{ }^{13} \mathrm{C}$ and ${ }^{19} \mathrm{~F}$ NMR spectra (3a'-i') S28 


\section{1. ${ }^{1} \mathrm{H},{ }^{13} \mathrm{C}$ and ${ }^{19} \mathrm{~F}$ NMR spectra (3a-z)}

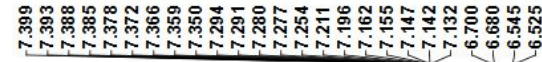

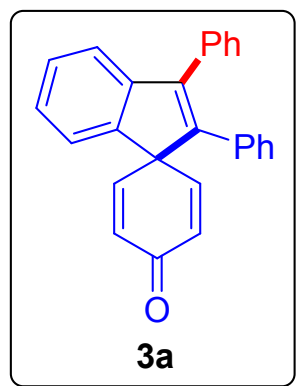

${ }^{1} \mathrm{H} \mathrm{NMR}\left(500 \mathrm{MHz}, \mathrm{CDCl}_{3}\right)$
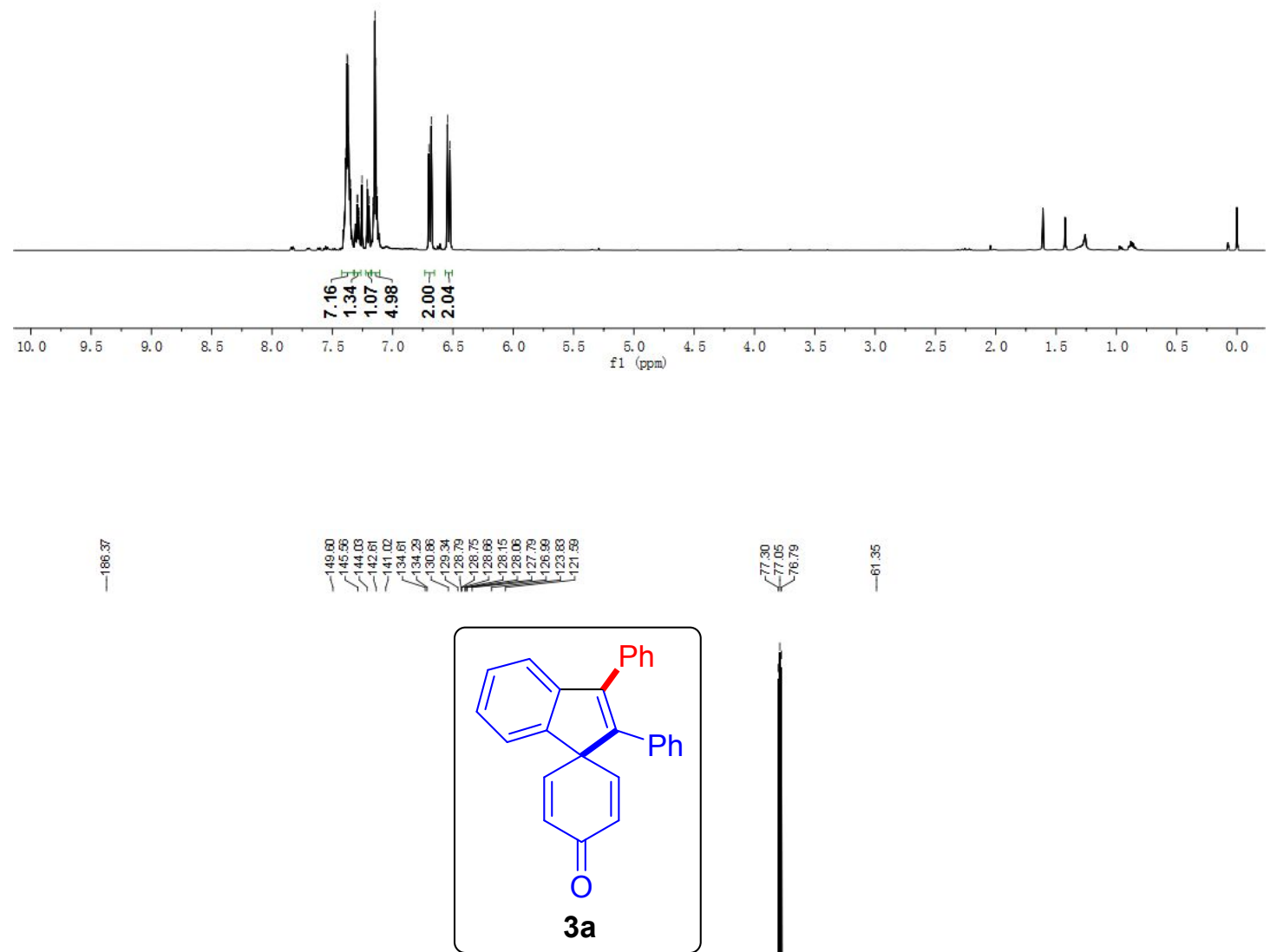

${ }^{13} \mathrm{C}$ NMR $\left(126 \mathrm{MHz}, \mathrm{CDCl}_{3}\right)$

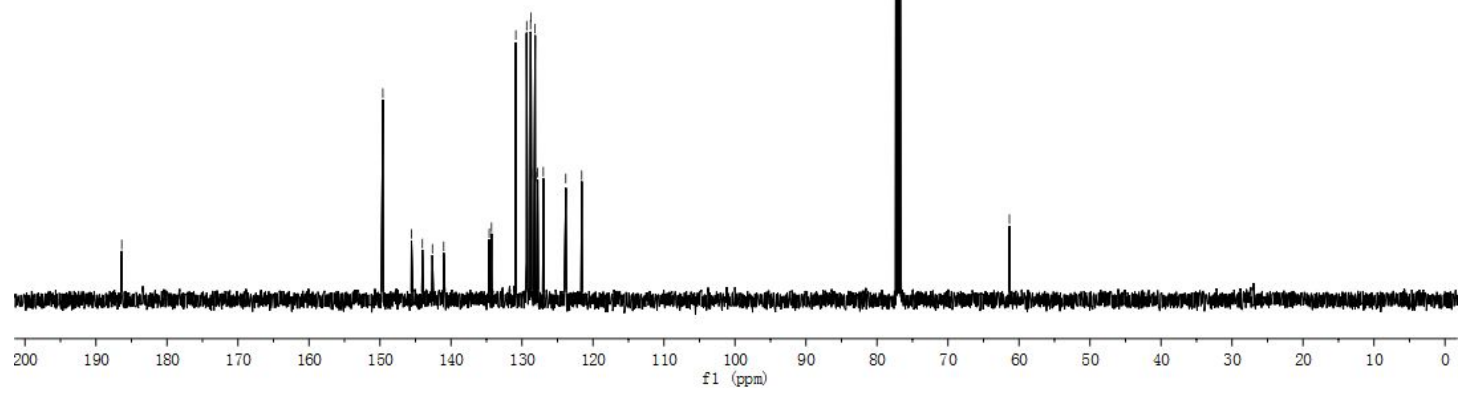




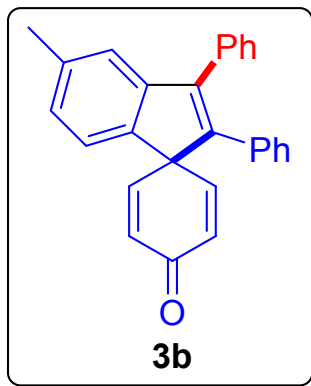

${ }^{1} \mathrm{H}$ NMR (500 MHz, $\mathrm{CDCl}_{3}$ )

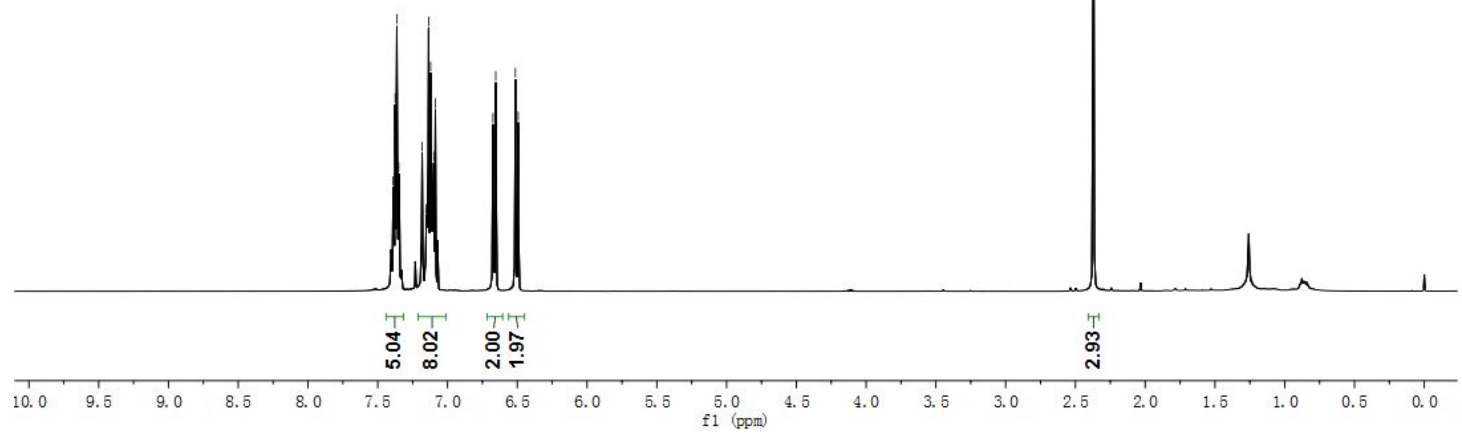

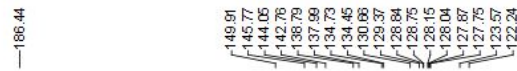

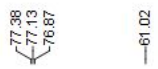

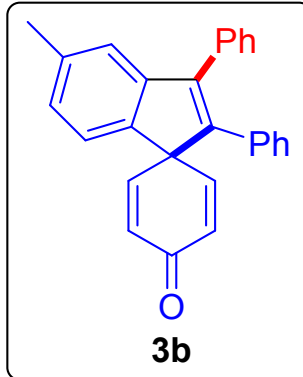

${ }^{13} \mathrm{C}$ NMR $\left(126 \mathrm{MHz}, \mathrm{CDCl}_{3}\right)$

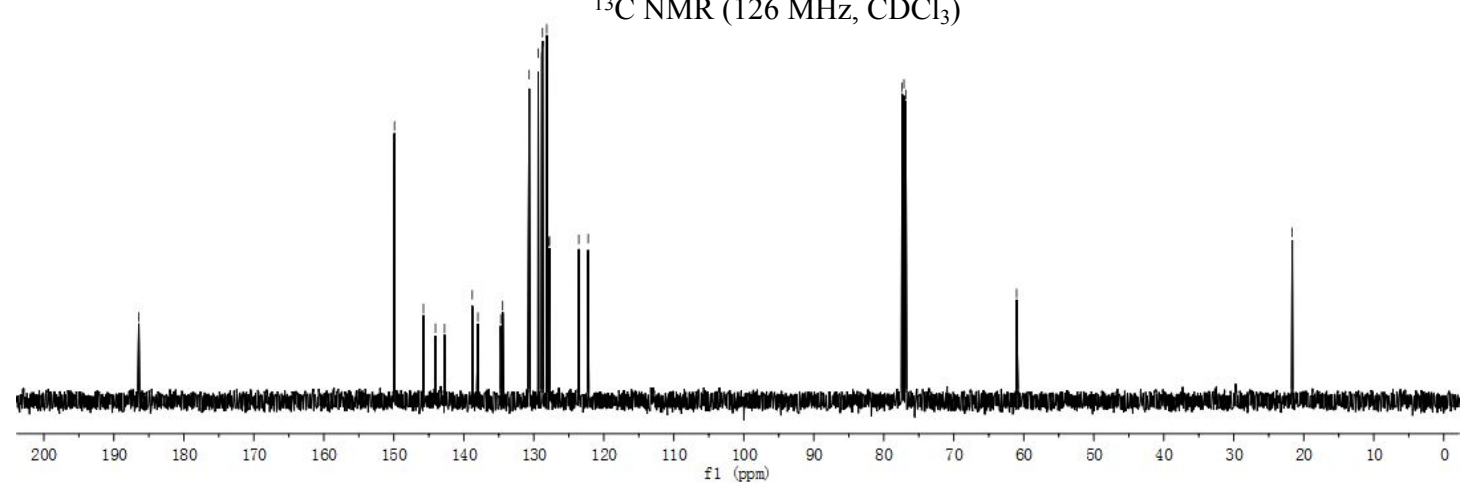



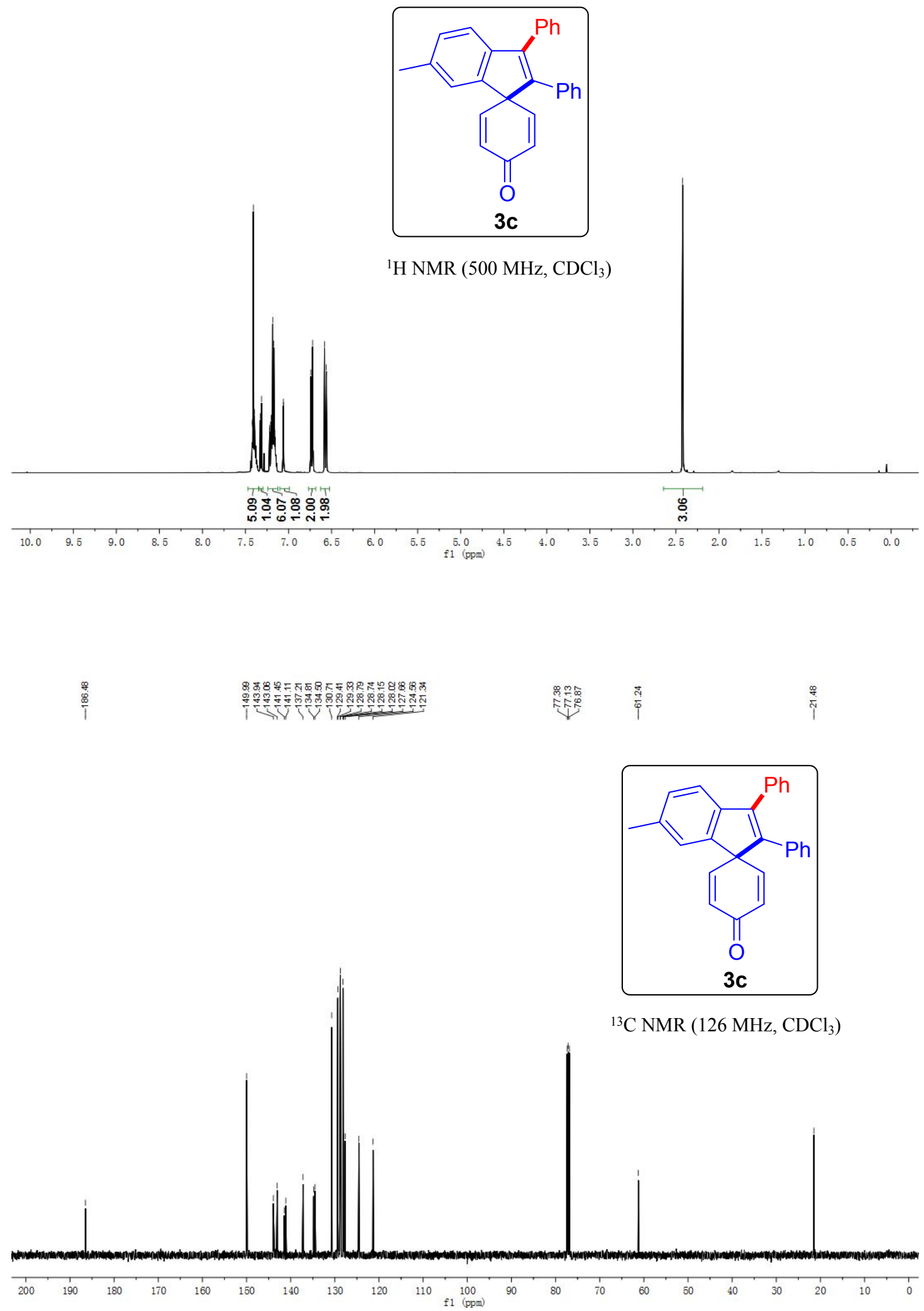


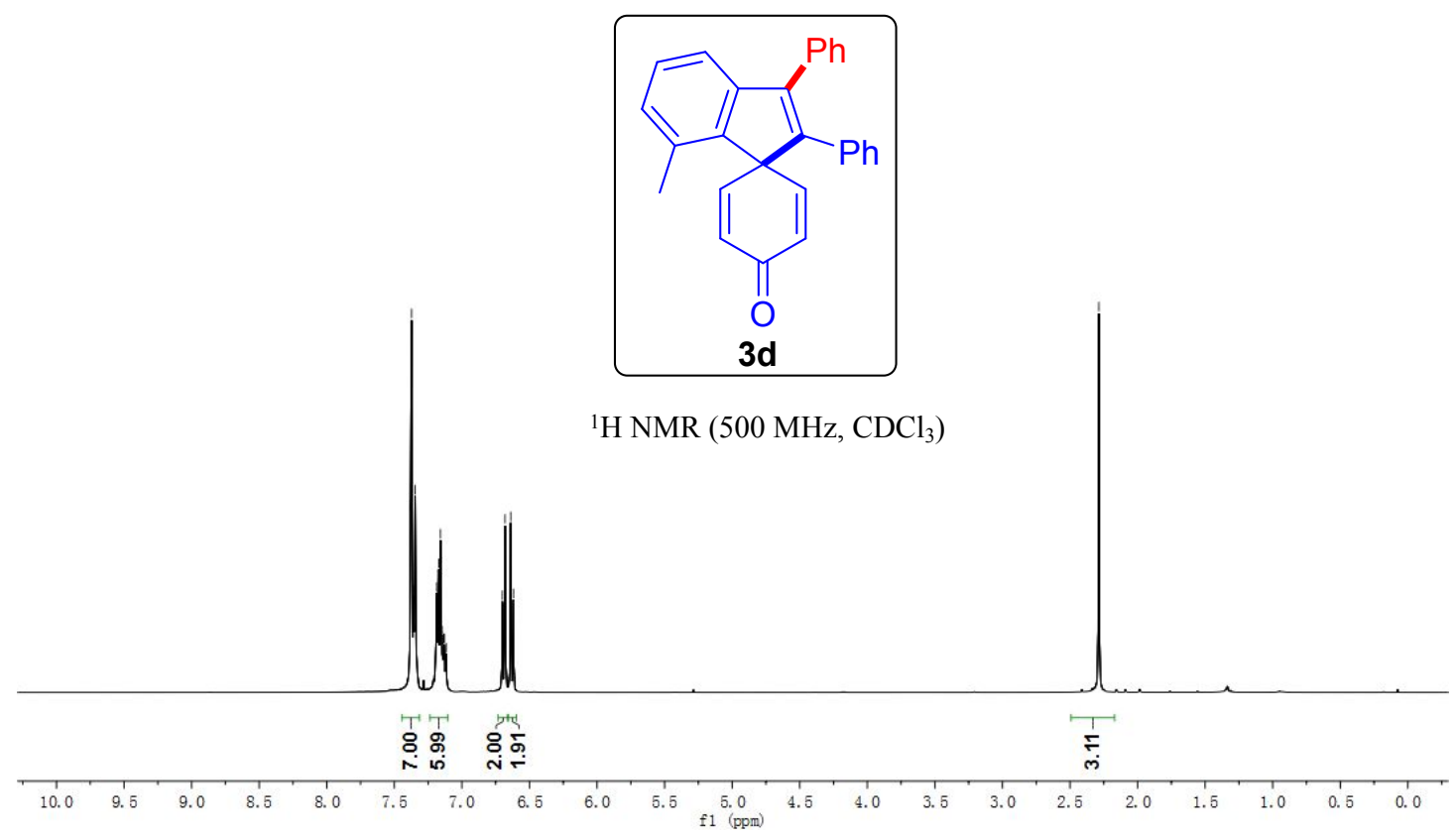

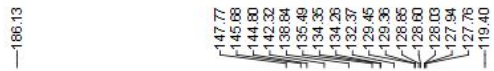
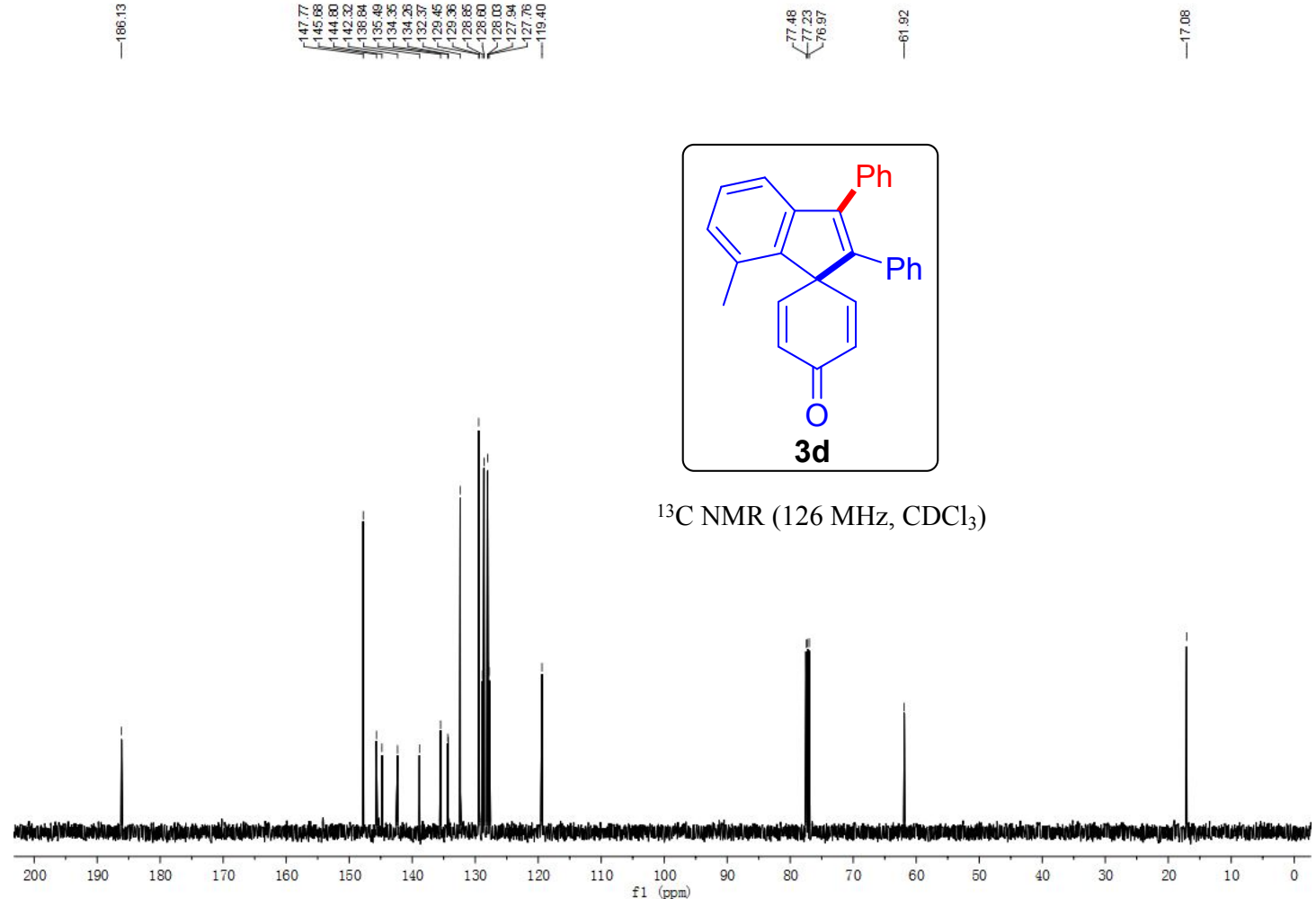


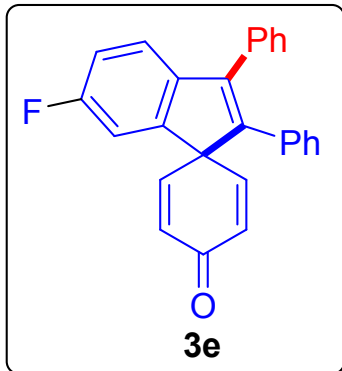

${ }^{1} \mathrm{H}$ NMR (500 MHz, $\mathrm{CDCl}_{3}$ )

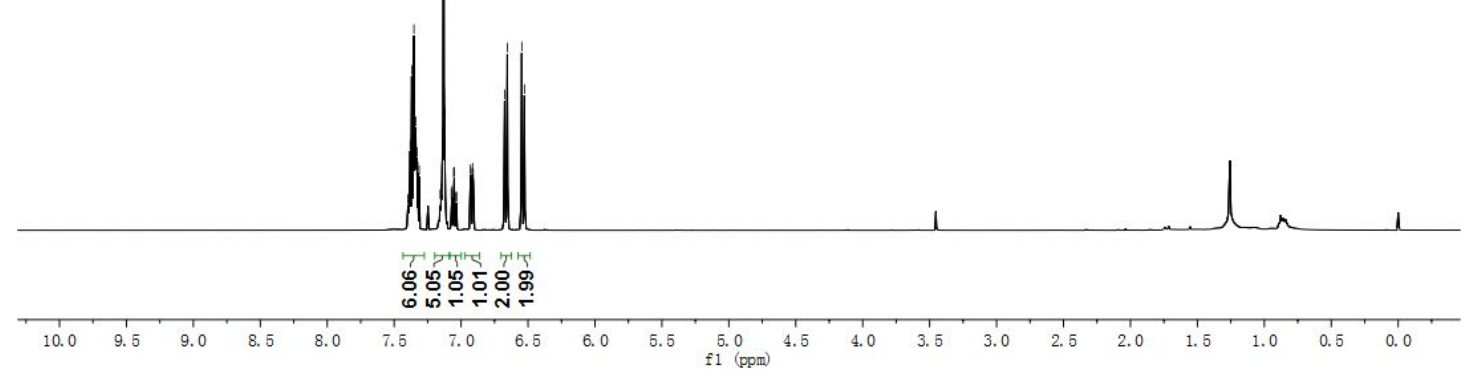

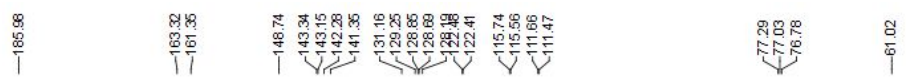

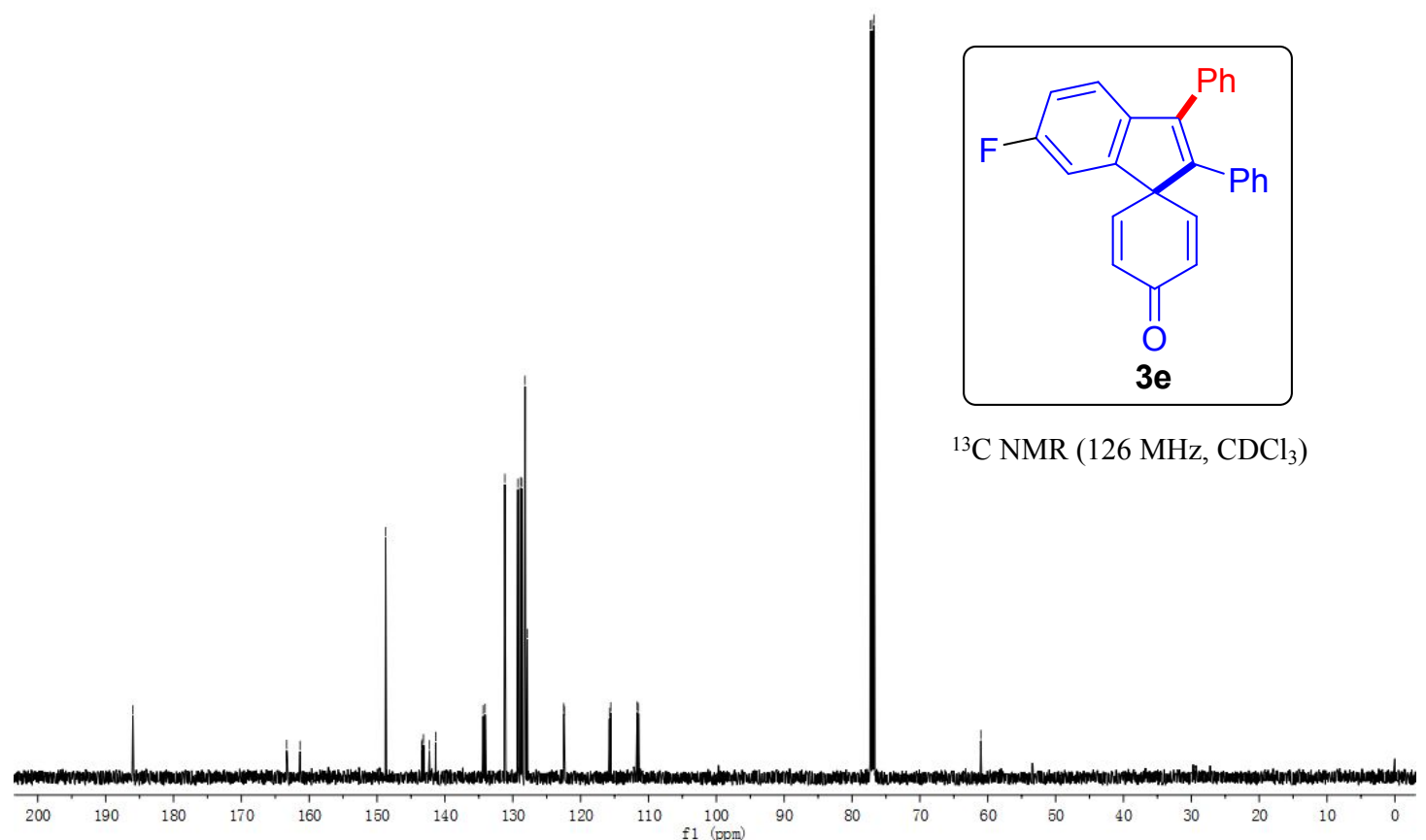


3e-F
STANDARD FLLORINE PARAETERS

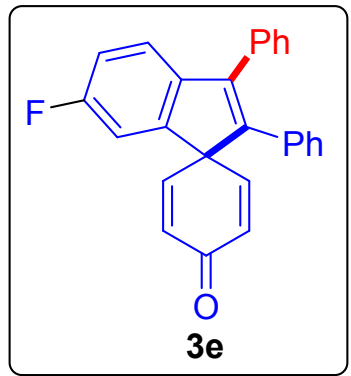

${ }^{19} \mathrm{~F}$ NMR $\left(470 \mathrm{MHz}, \mathrm{CDCl}_{3}\right)$

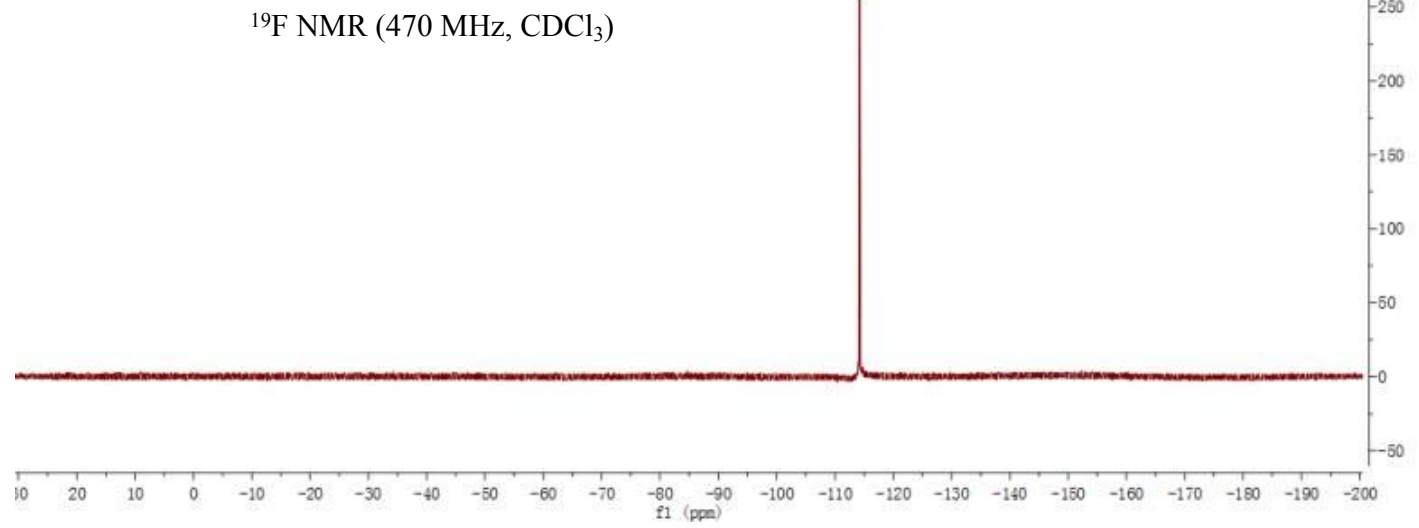

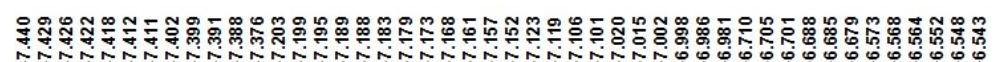

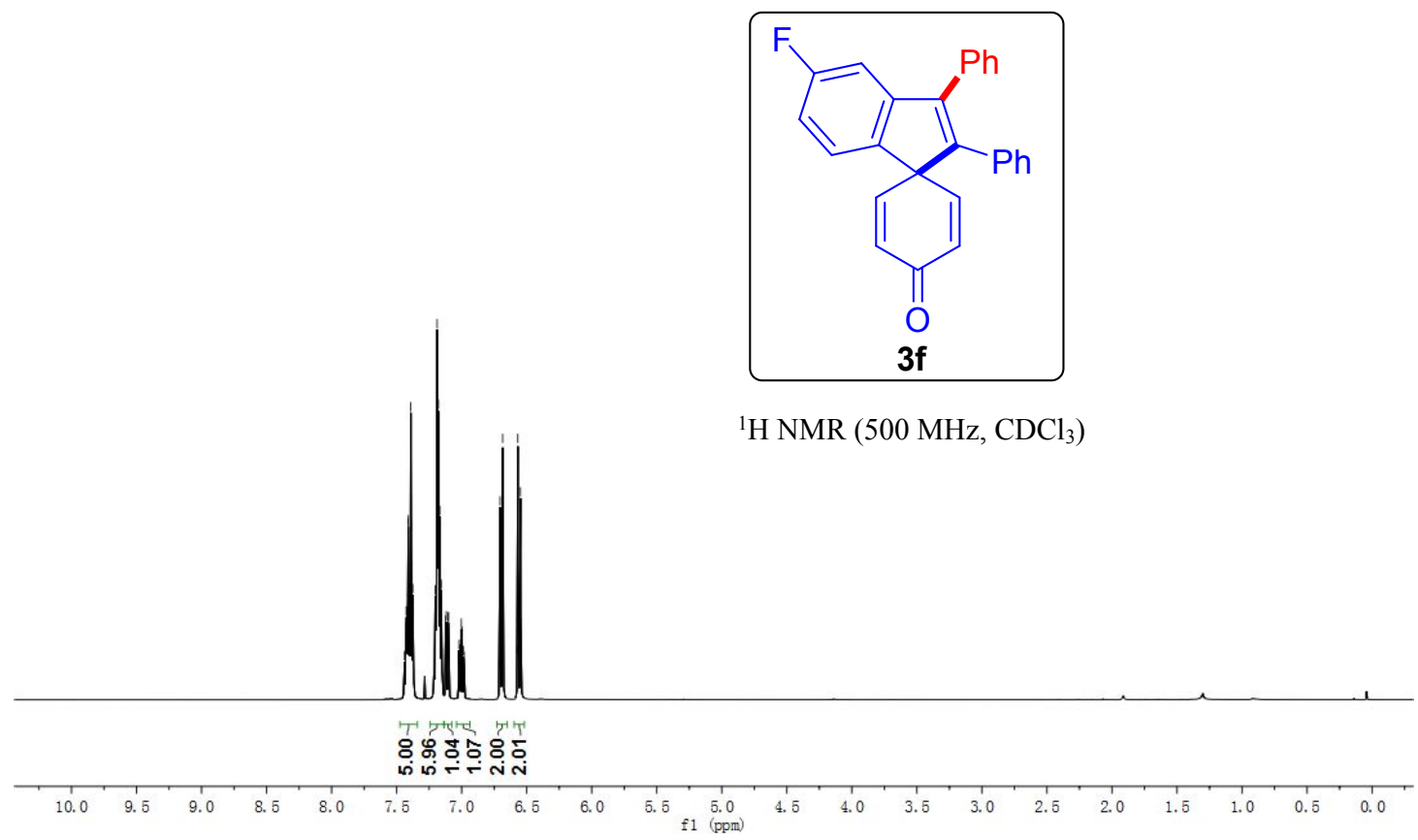




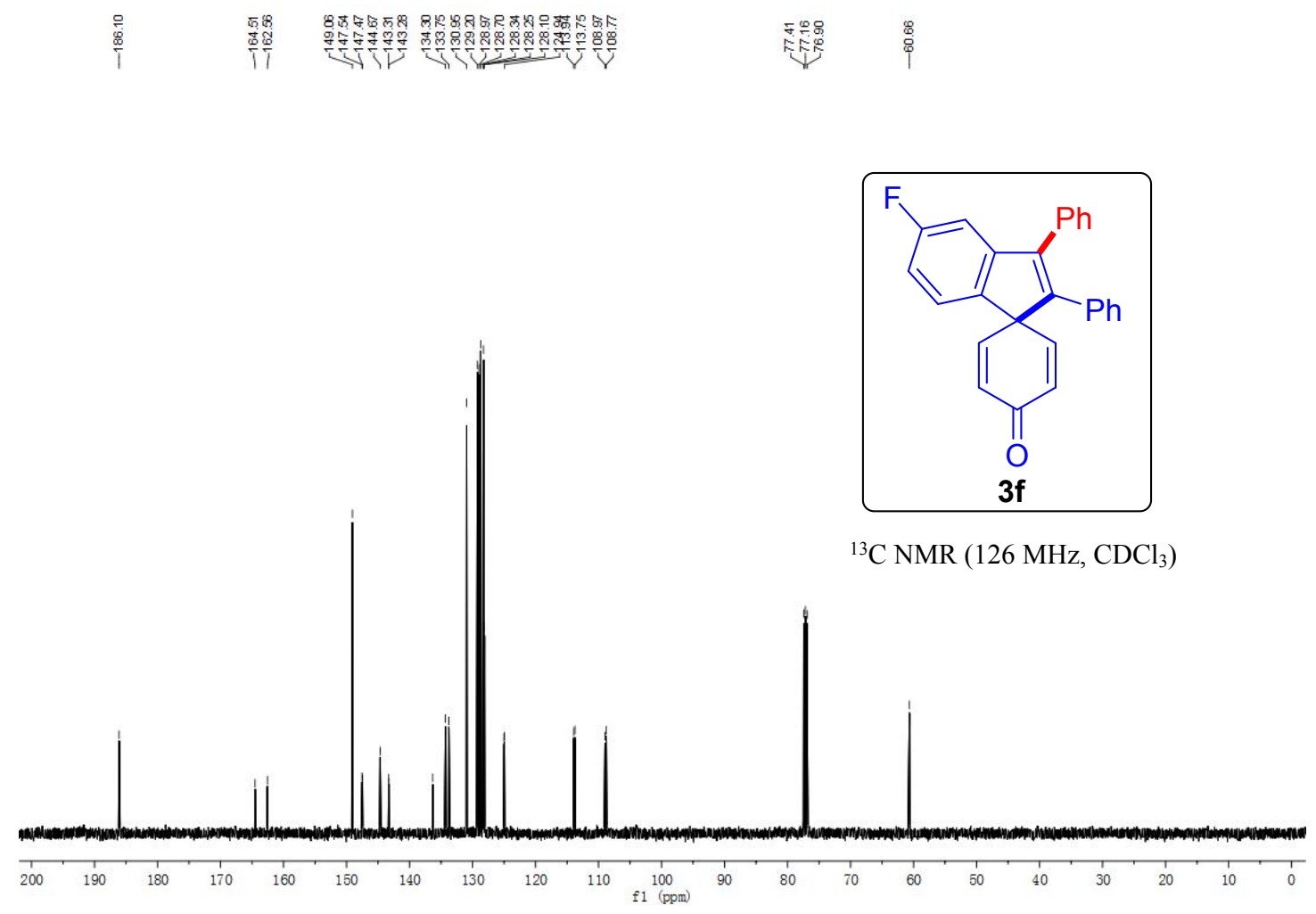

3e-F
STANDARD FLUORINE PARAETERS

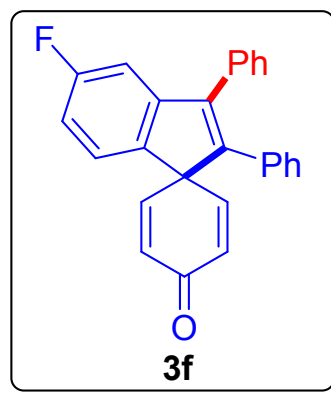

${ }^{19} \mathrm{~F}$ NMR (470 MHz, $\mathrm{CDCl}_{3}$ )

\begin{tabular}{l}
-300 \\
-2200 \\
-2100 \\
-2000 \\
-1900 \\
-800 \\
-1700 \\
-1600 \\
-1600 \\
-1400 \\
-1300 \\
-1200 \\
-1100 \\
-000 \\
-900 \\
-800 \\
-700 \\
-600 \\
-500 \\
-400 \\
-300 \\
-200 \\
-100 \\
-100 \\
-200 \\
-100 \\
\hline
\end{tabular} 


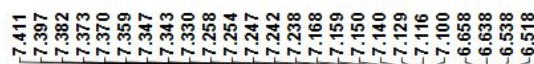

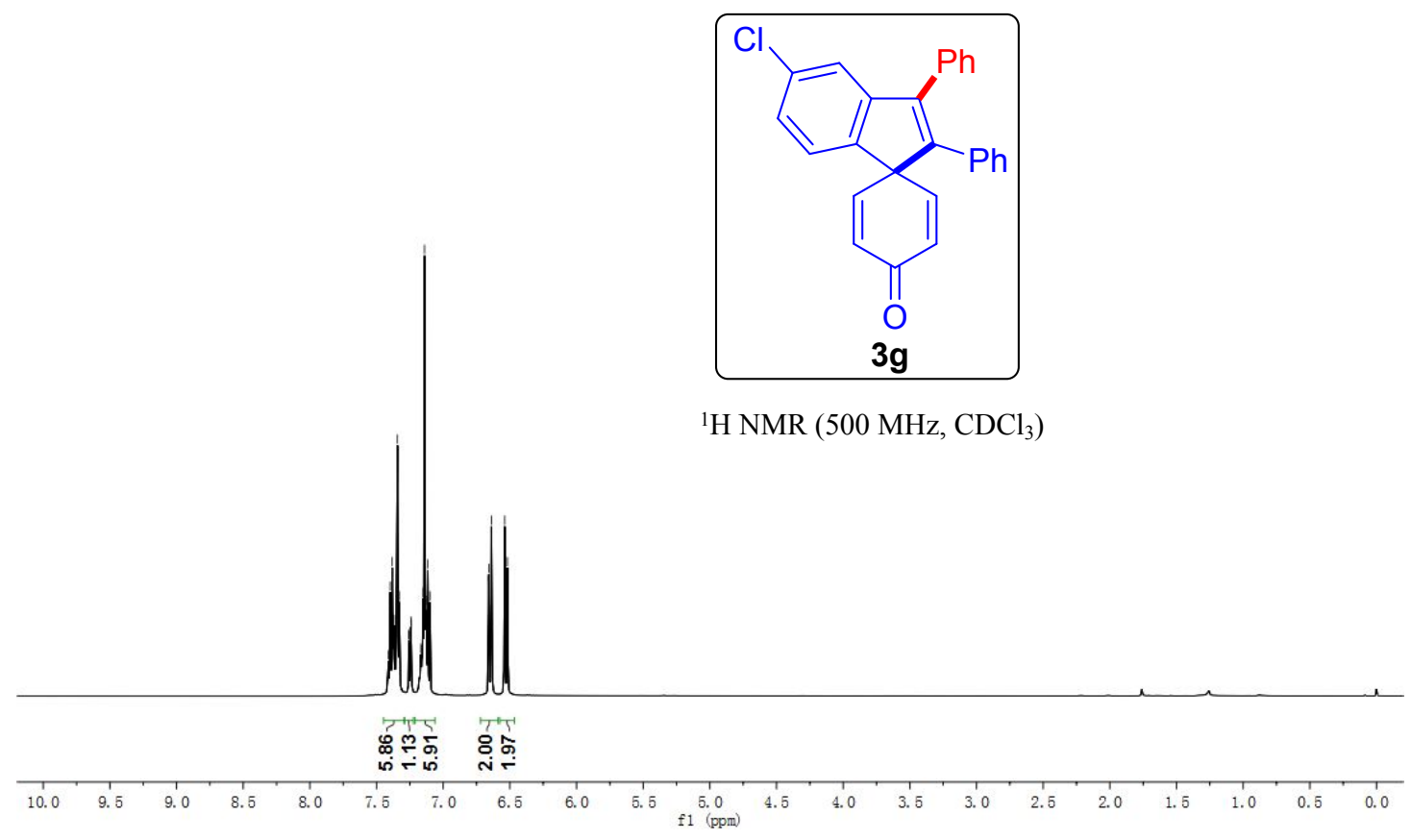

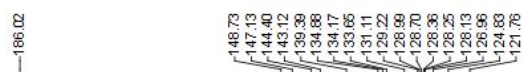
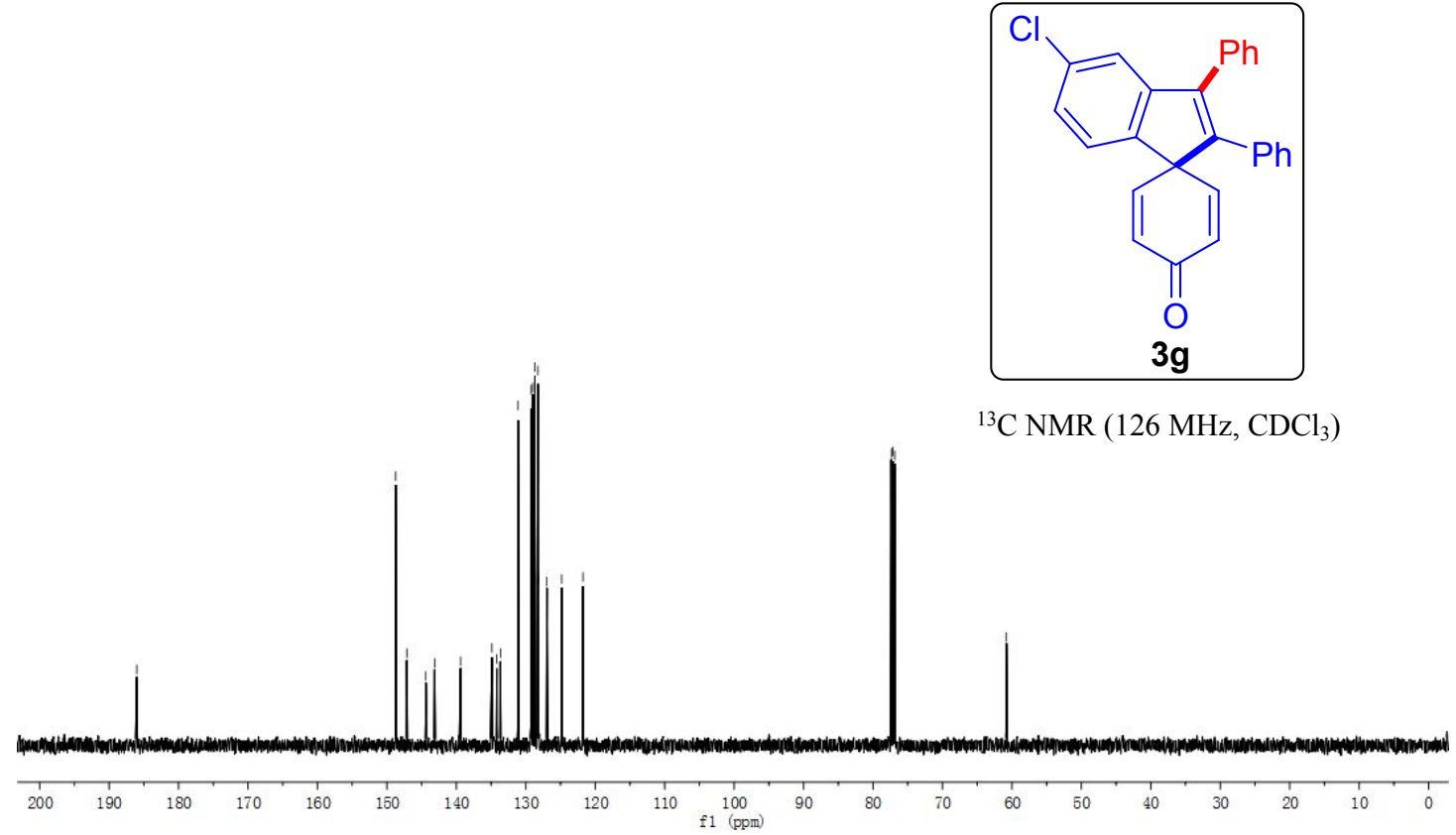

${ }^{13} \mathrm{C}$ NMR (126 MHz, $\mathrm{CDCl}_{3}$ ) 


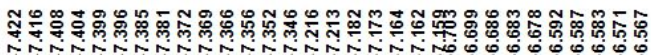

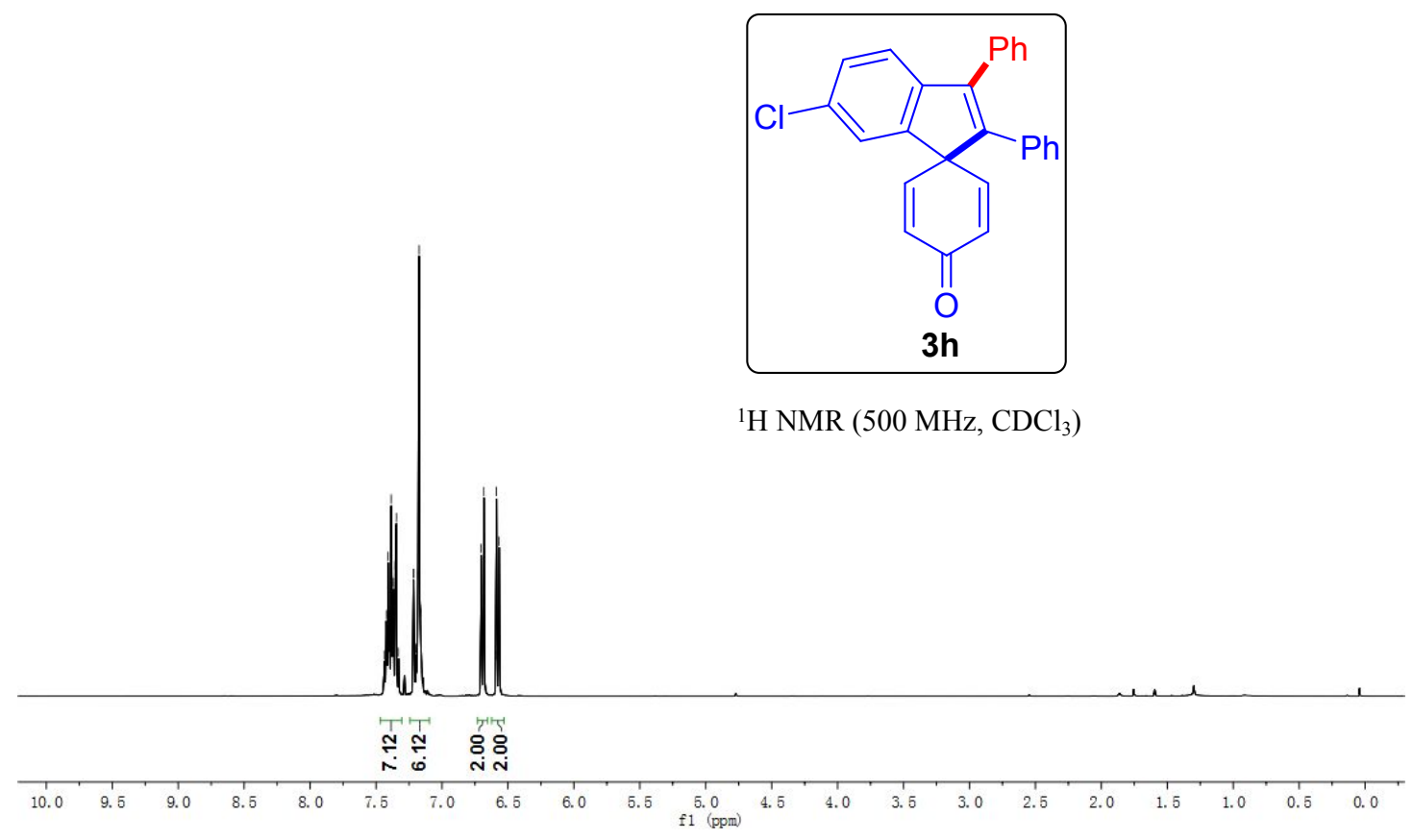

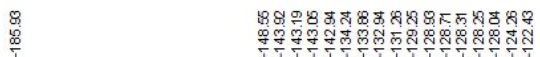

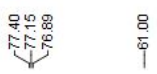
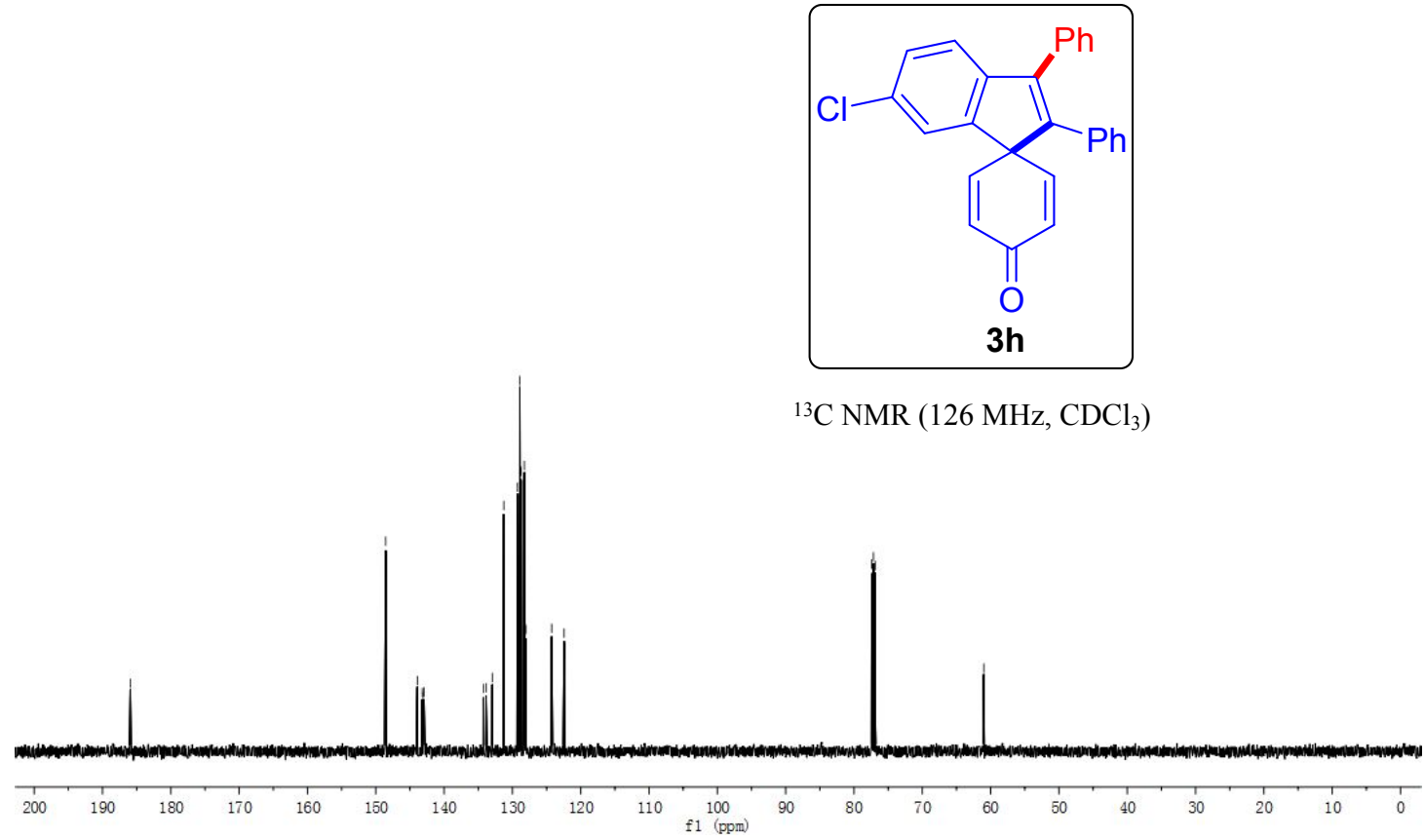

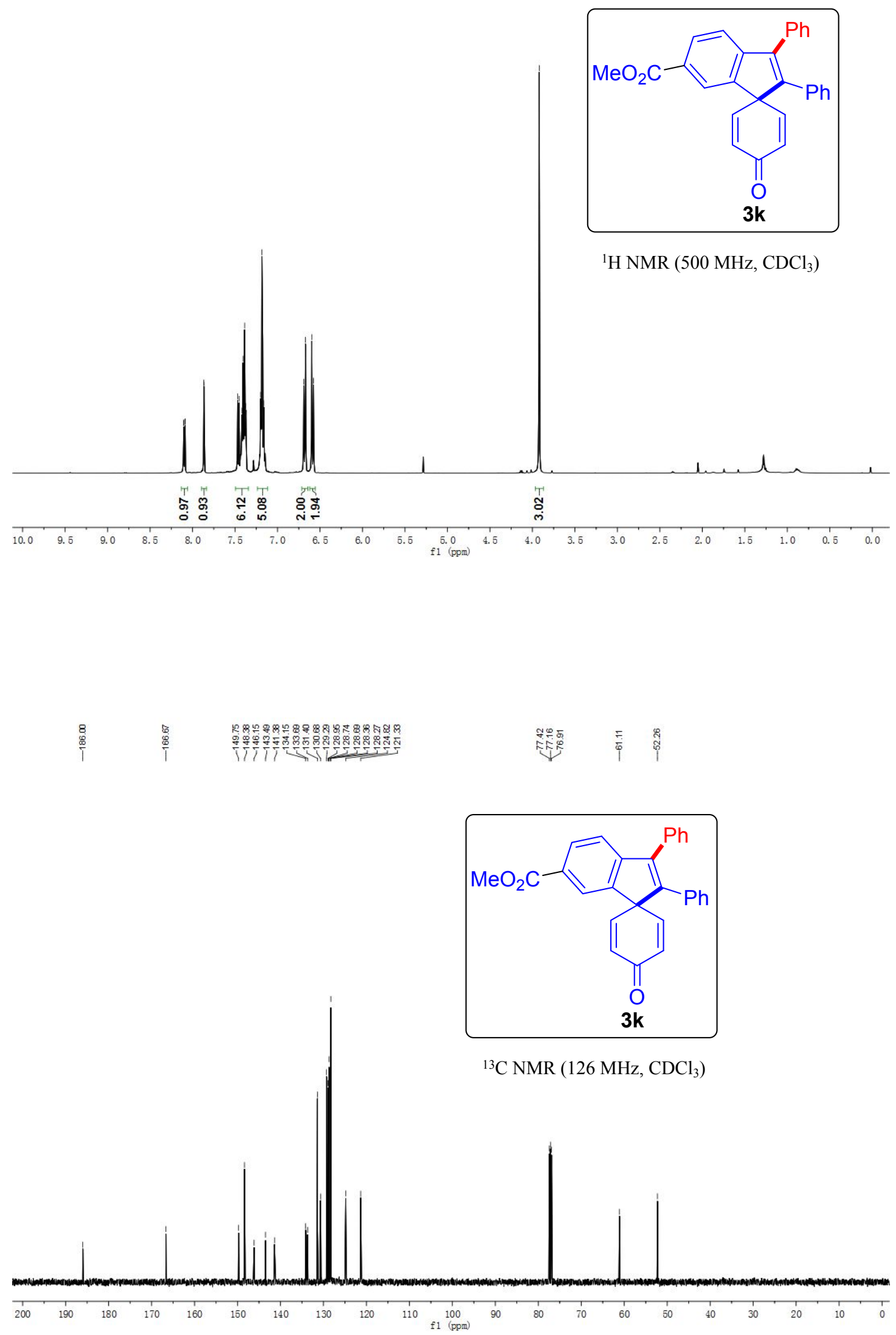


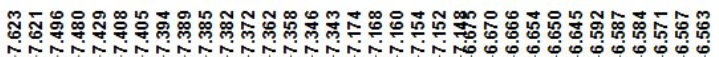
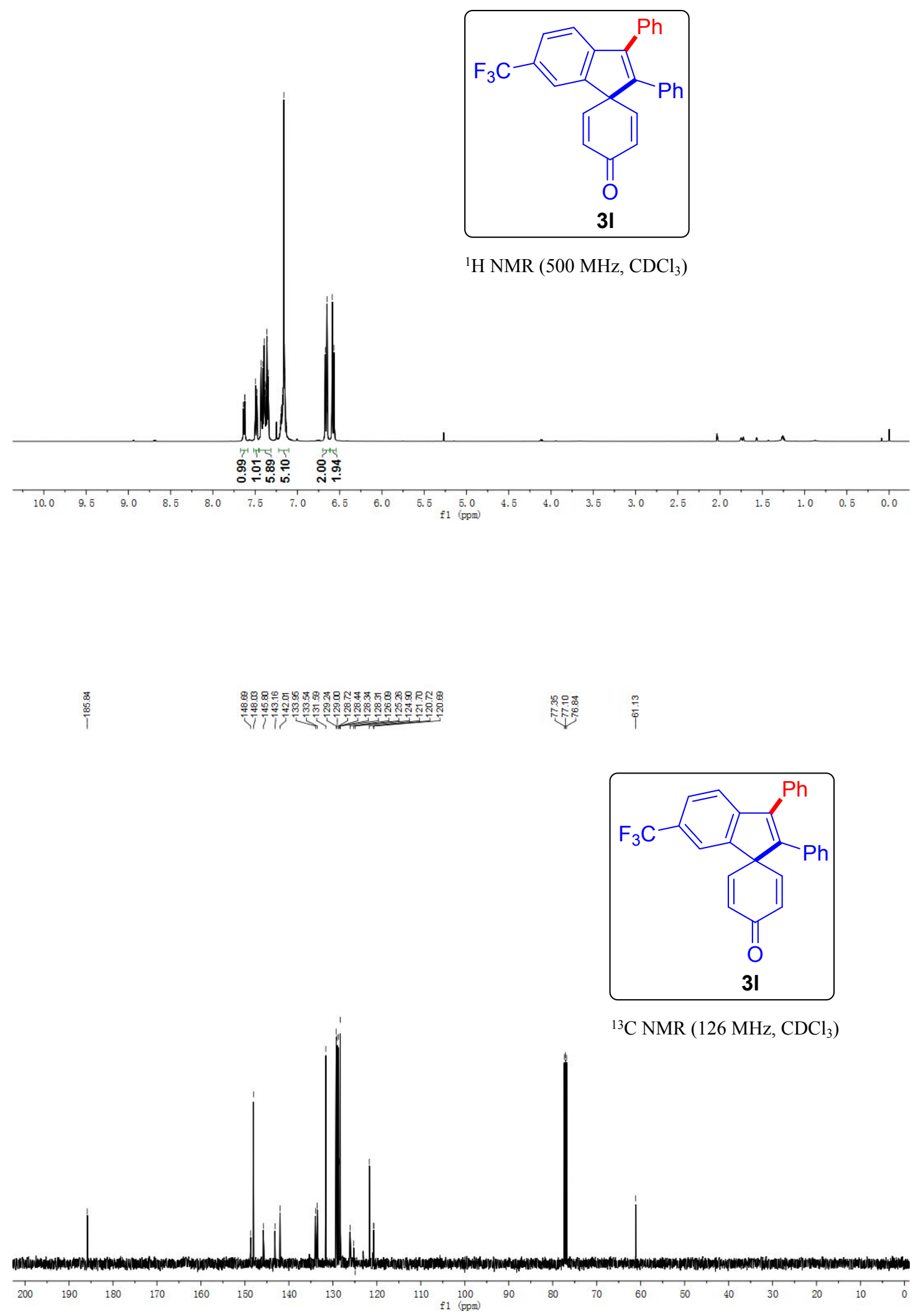


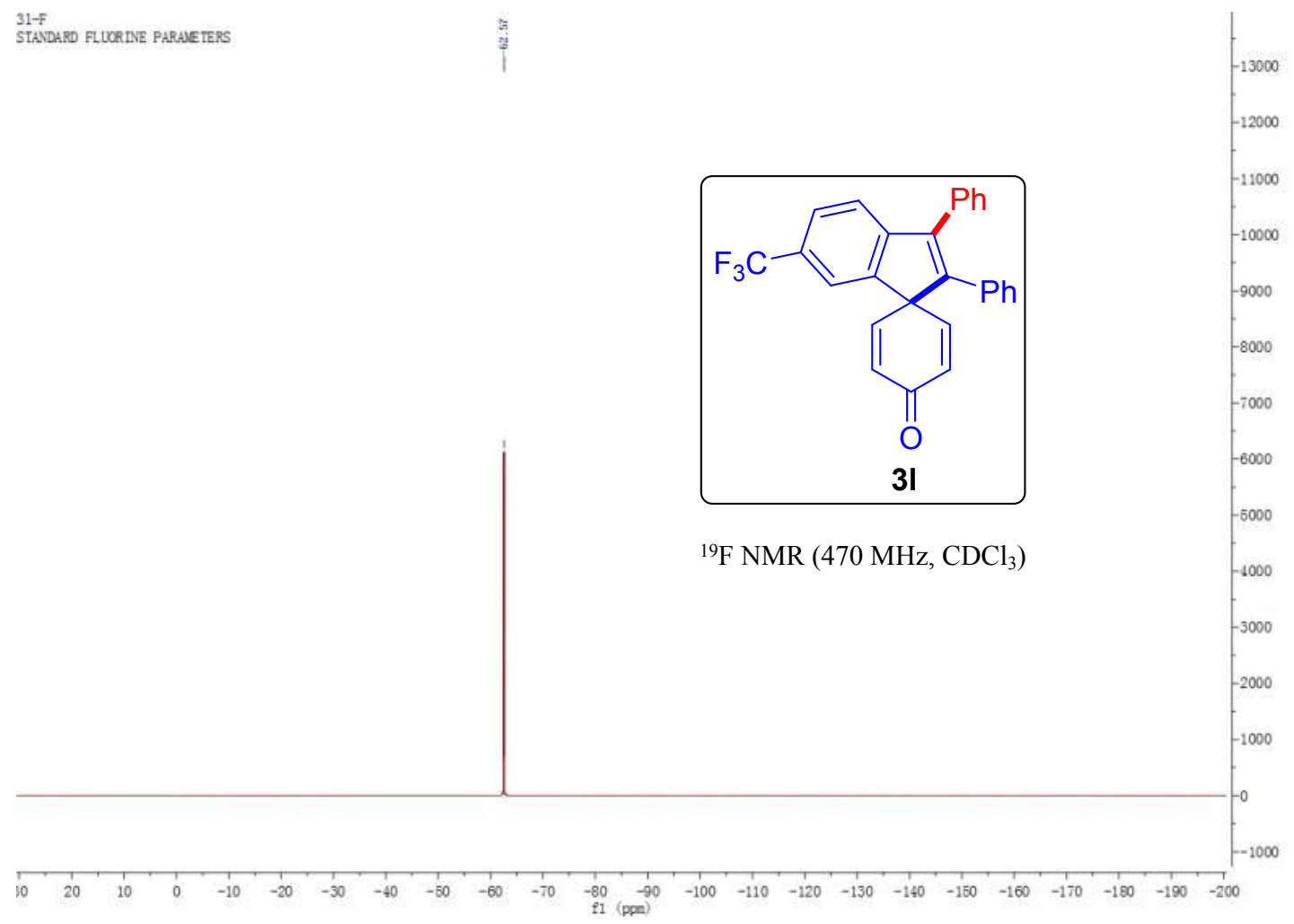

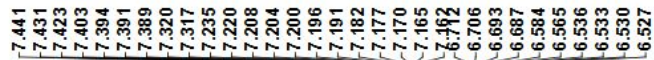

జ్ูำ

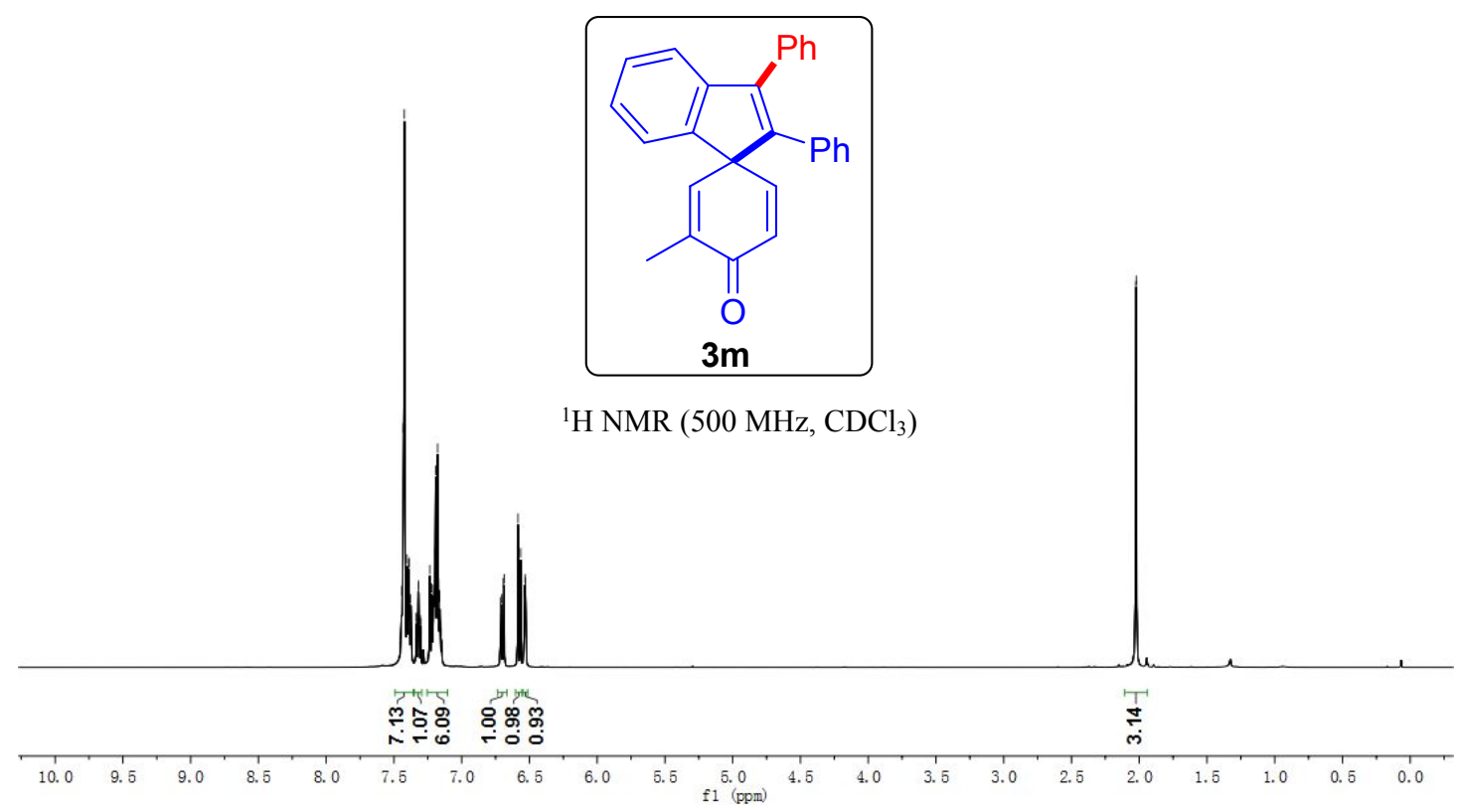




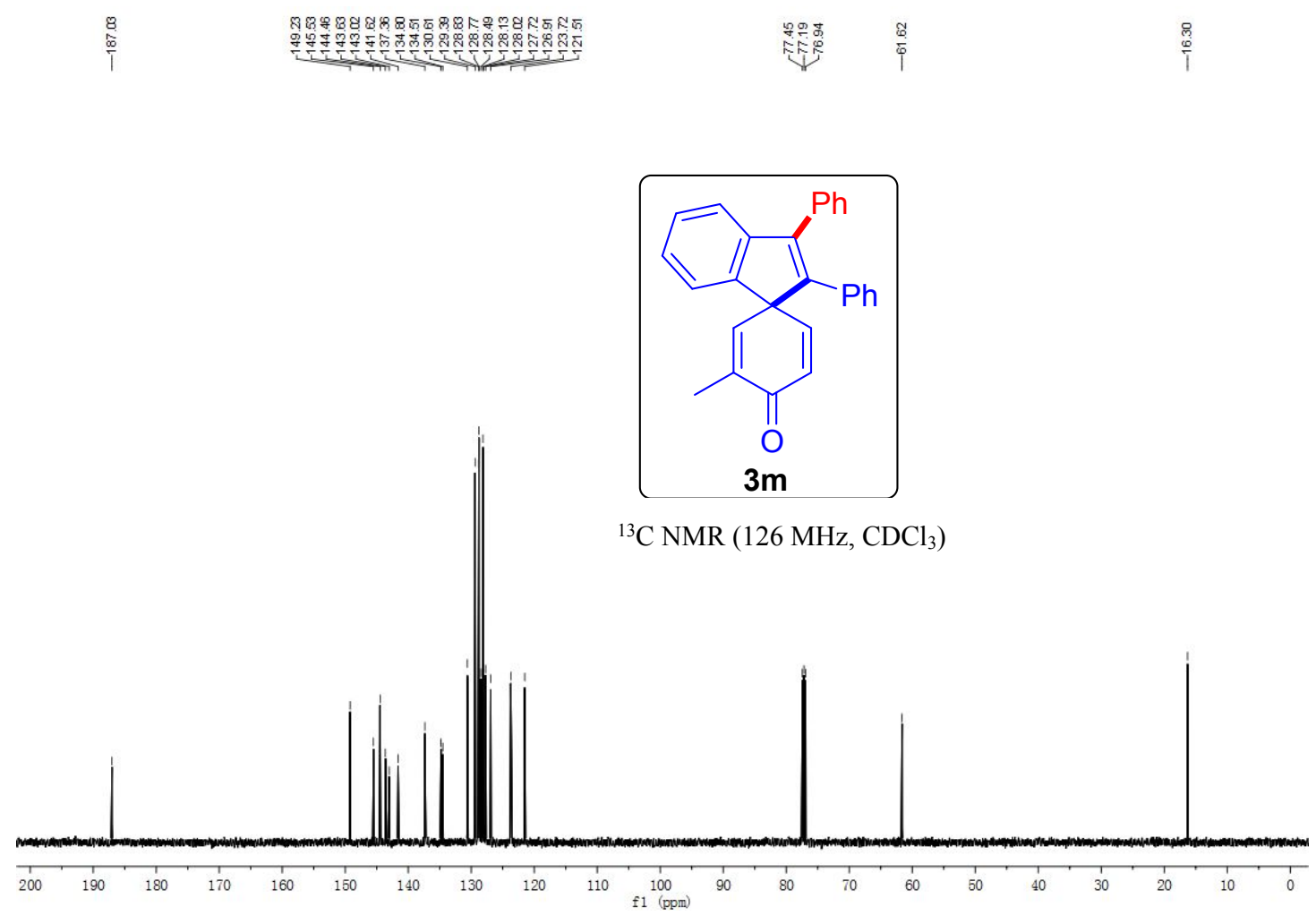

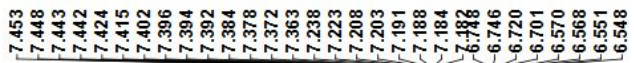

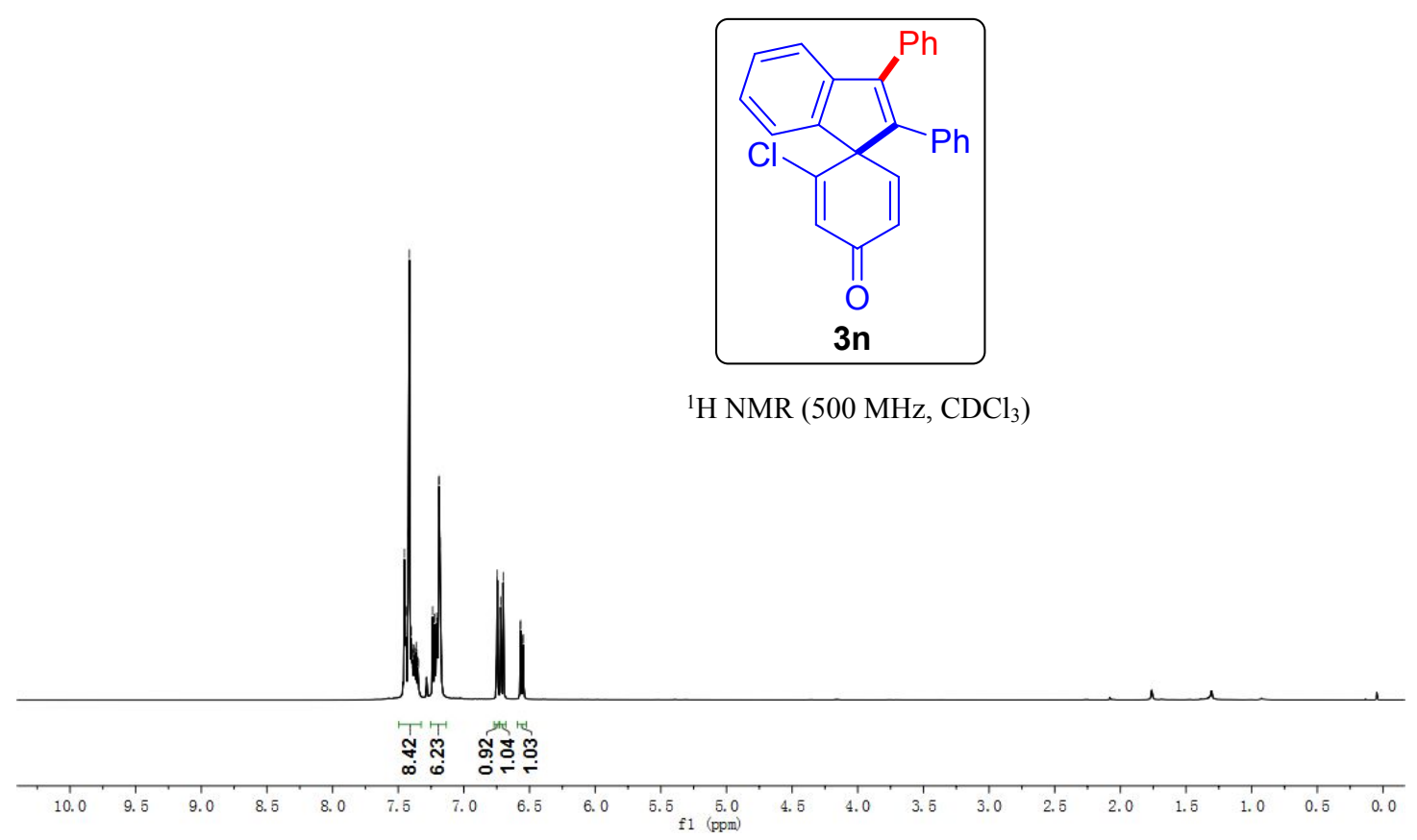




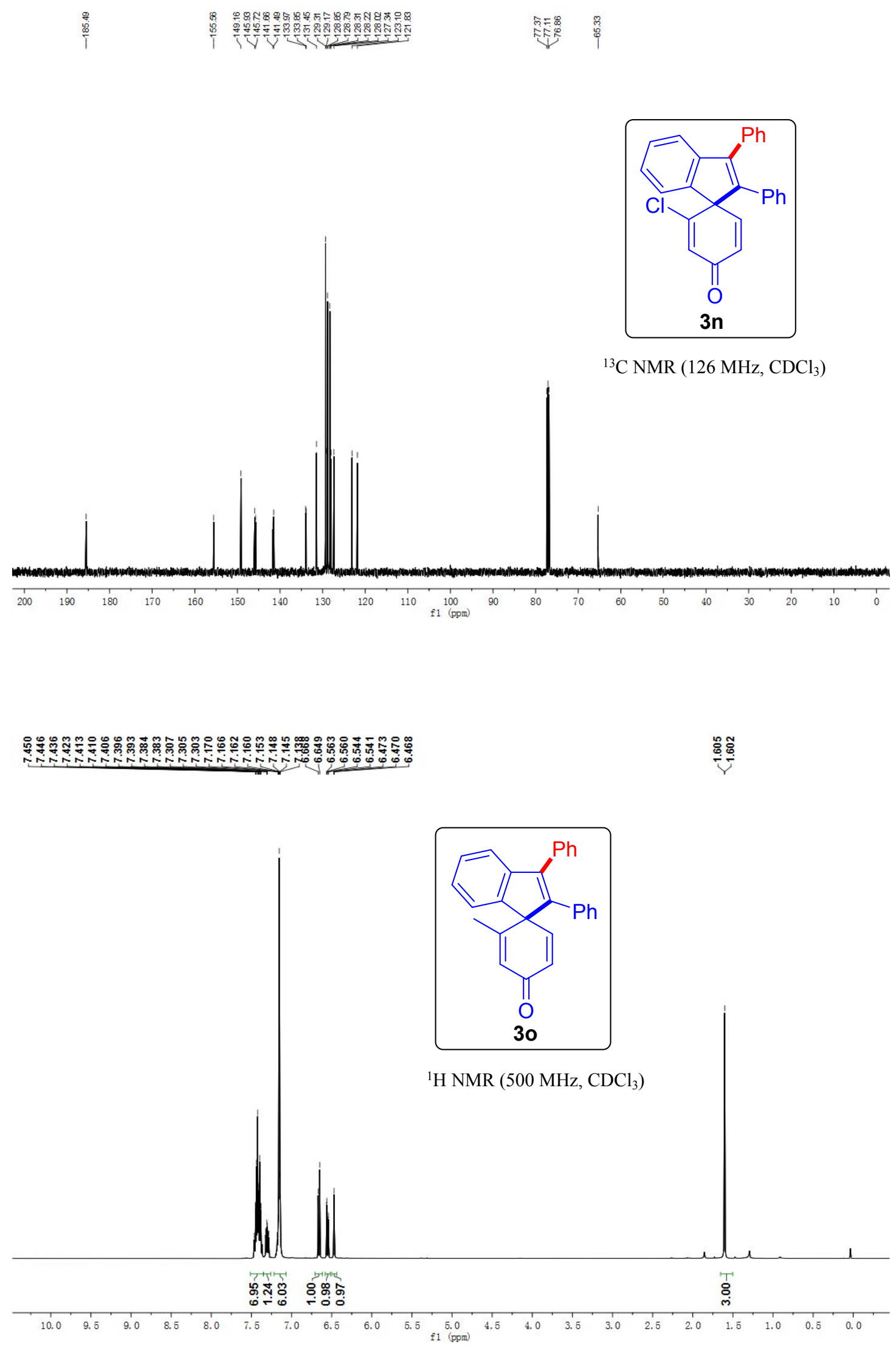




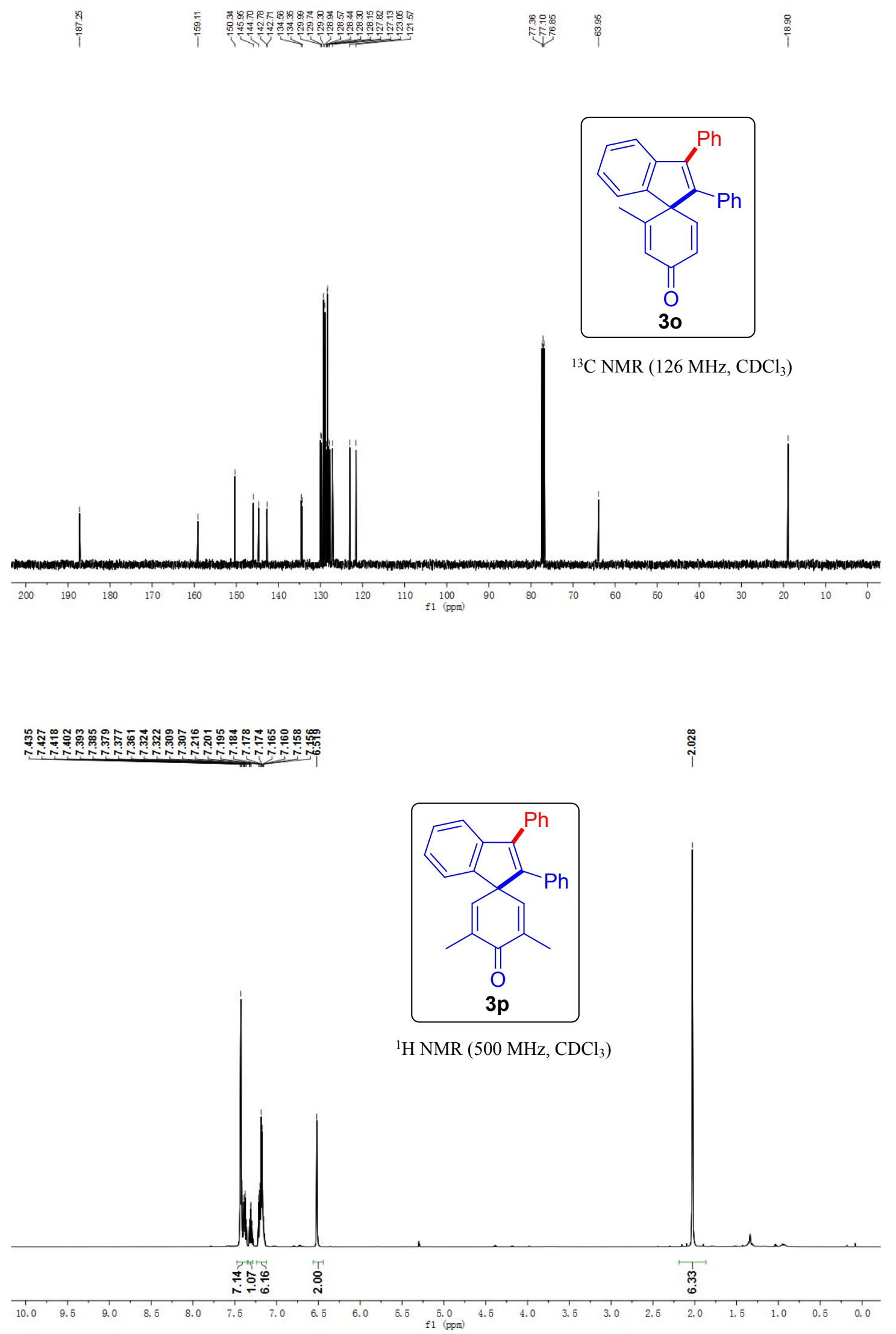




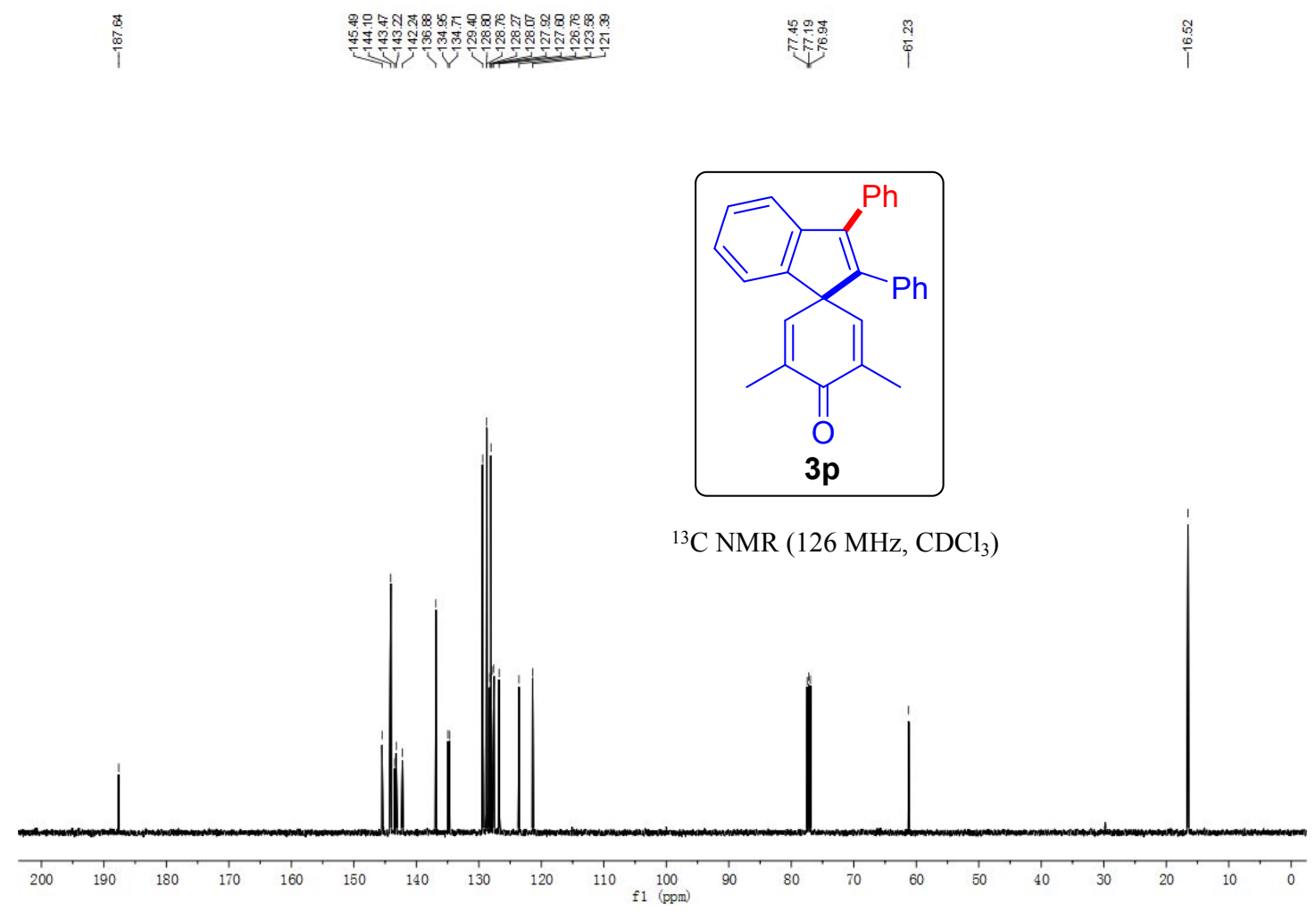

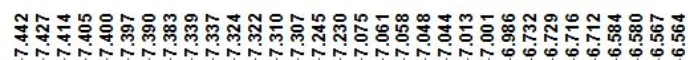

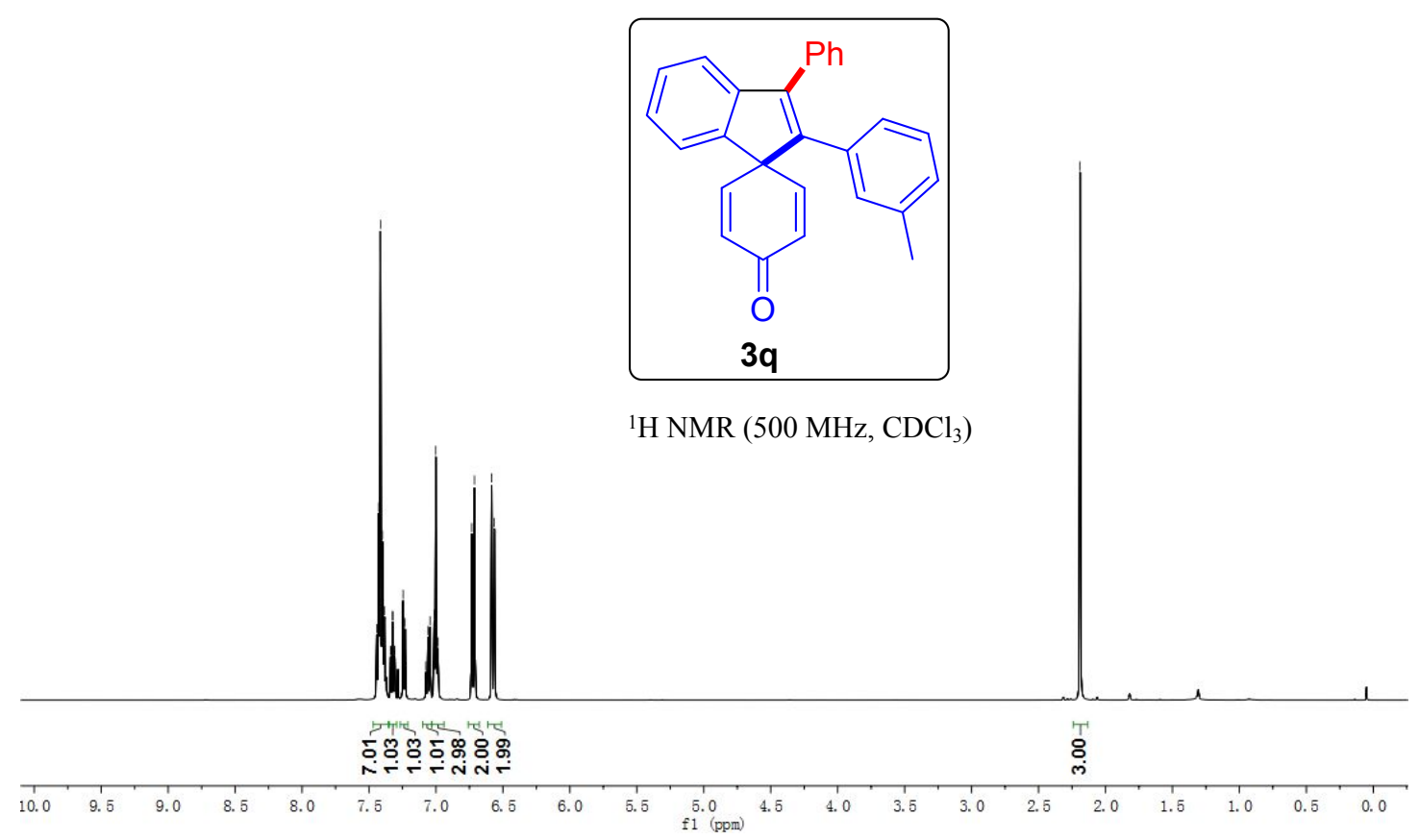




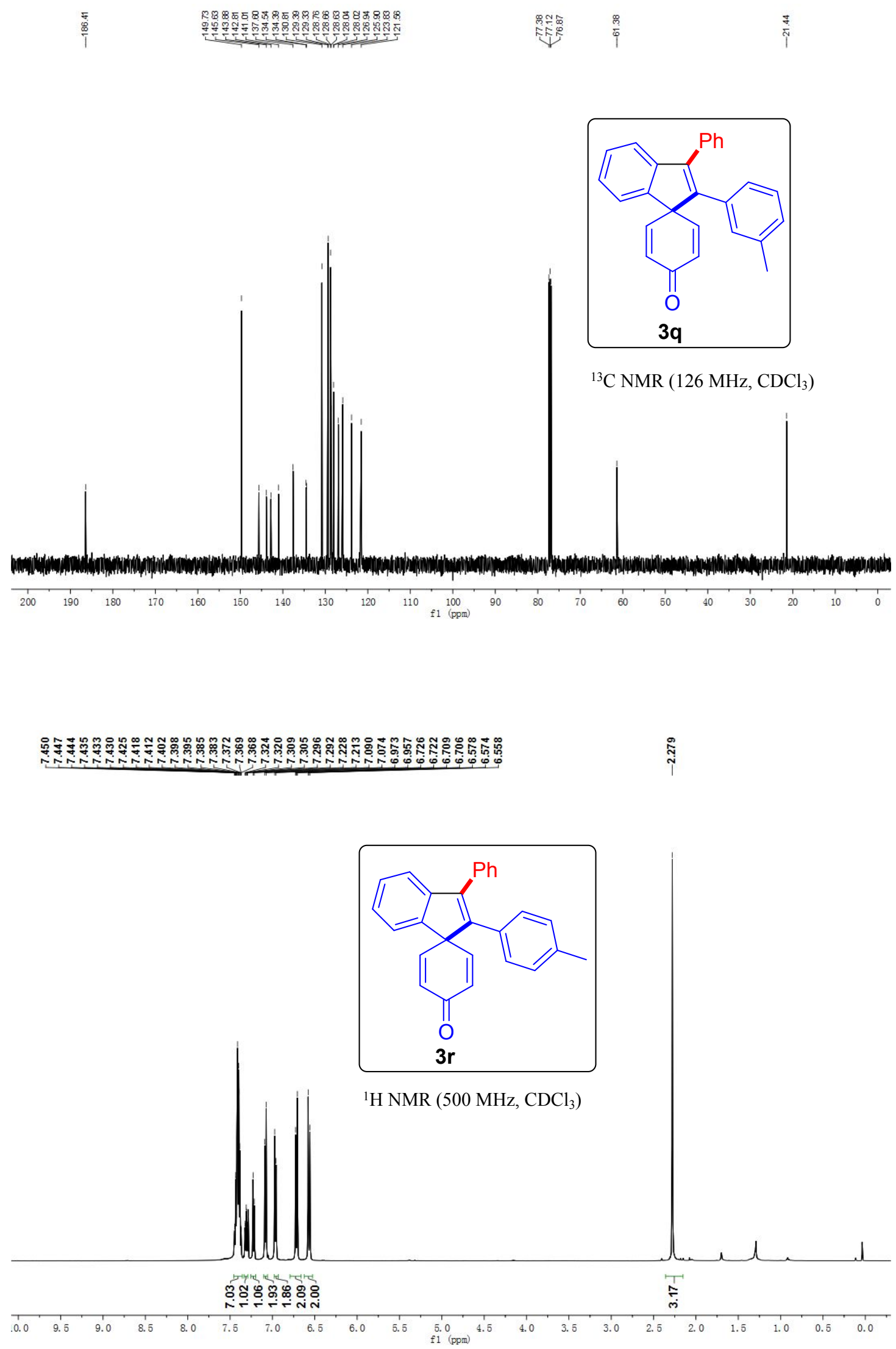




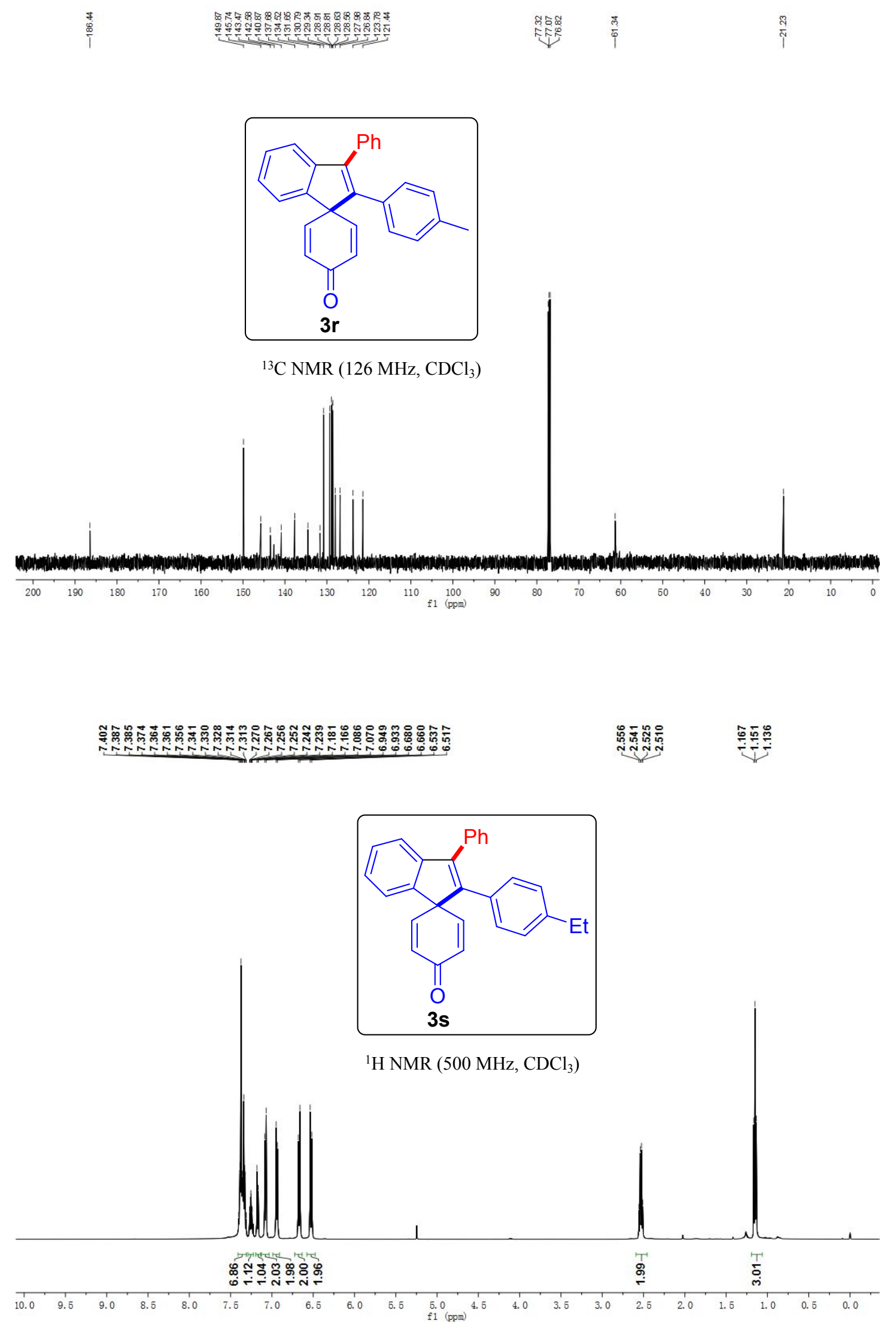




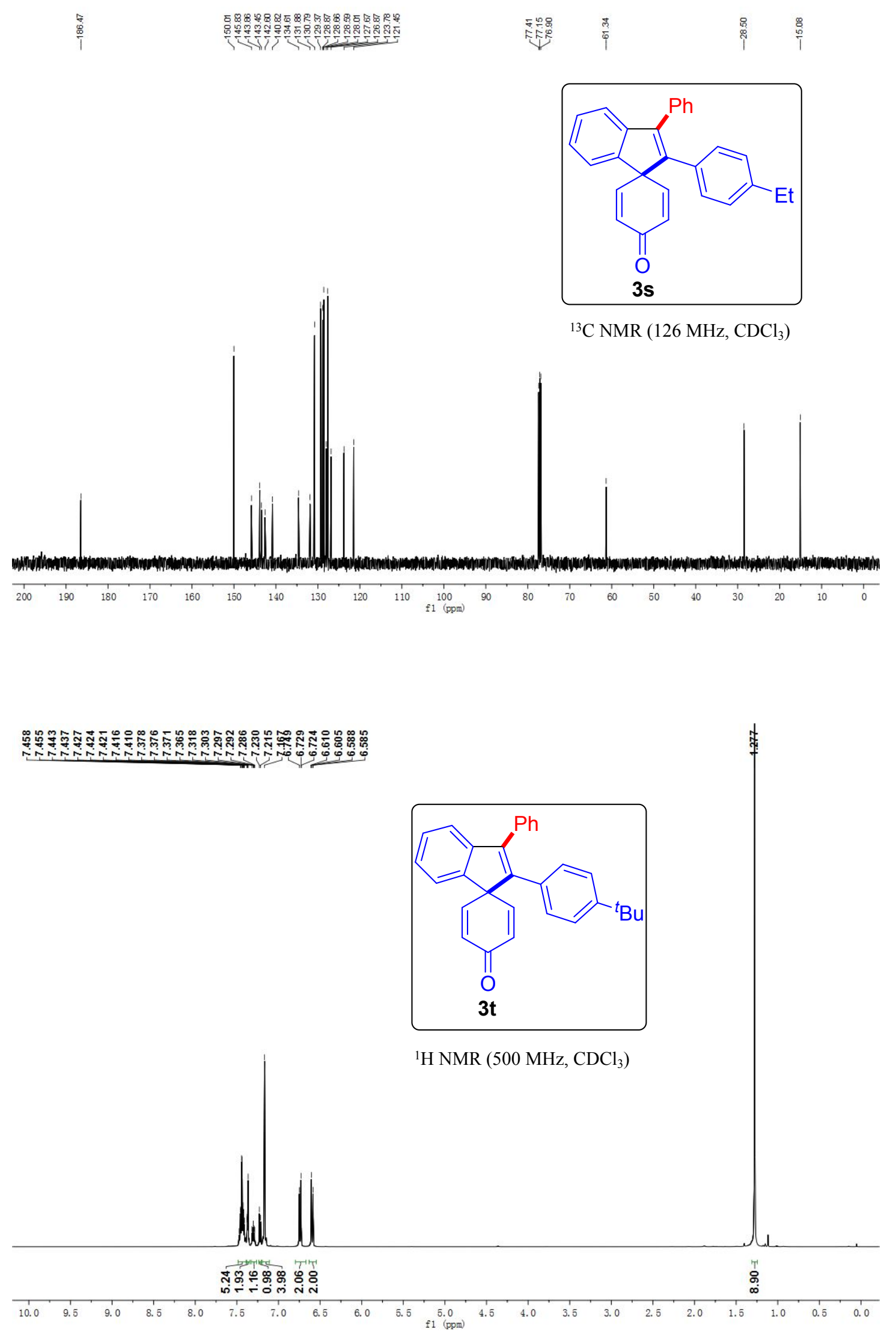



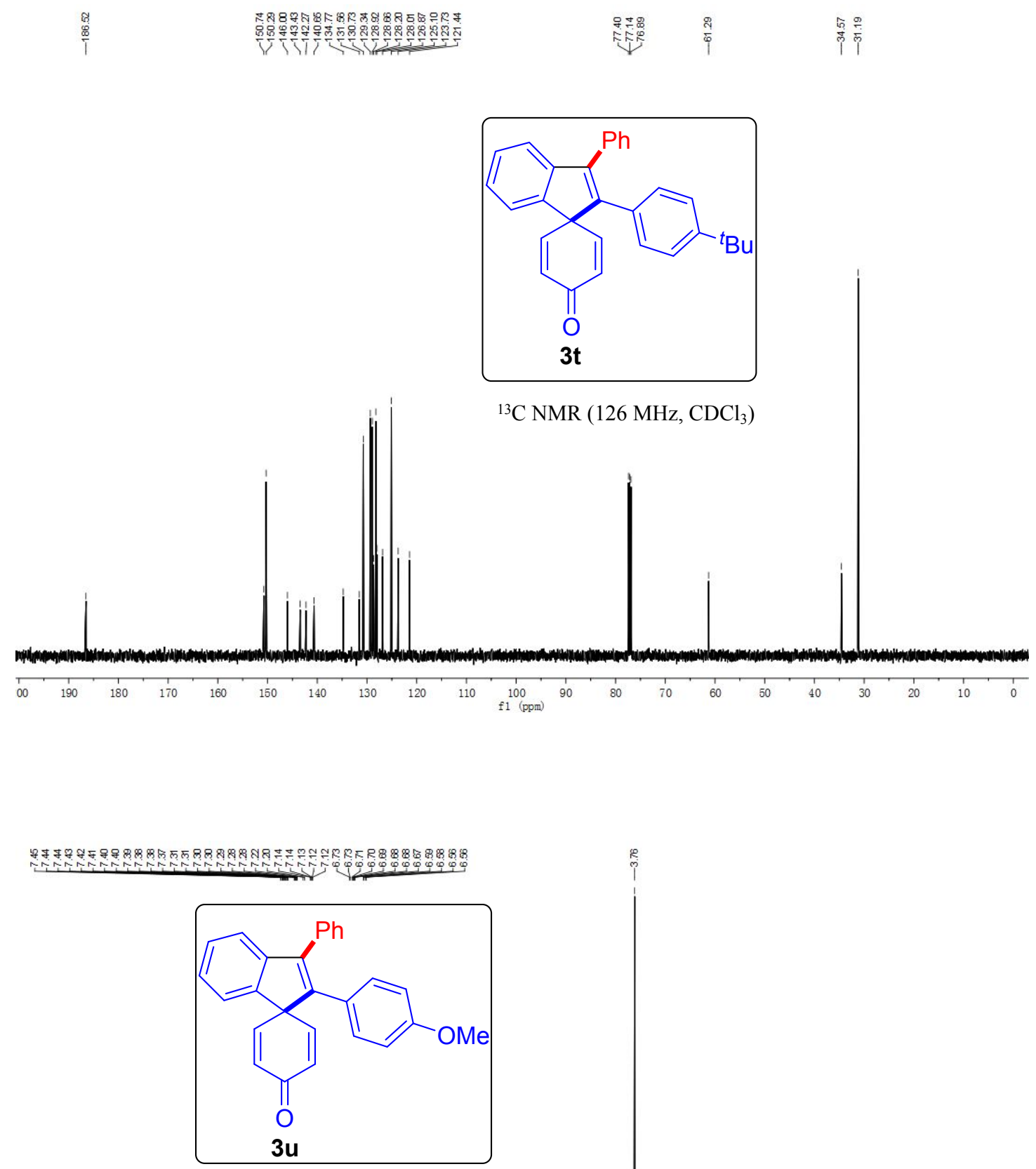

${ }^{1} \mathrm{H}$ NMR (500 MHz, $\mathrm{CDCl}_{3}$ )

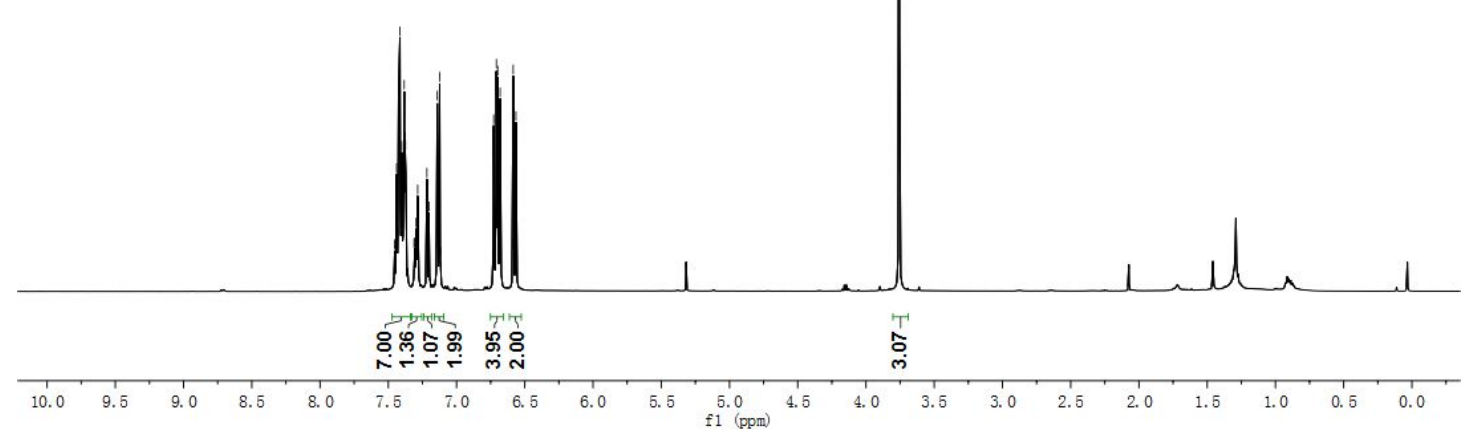




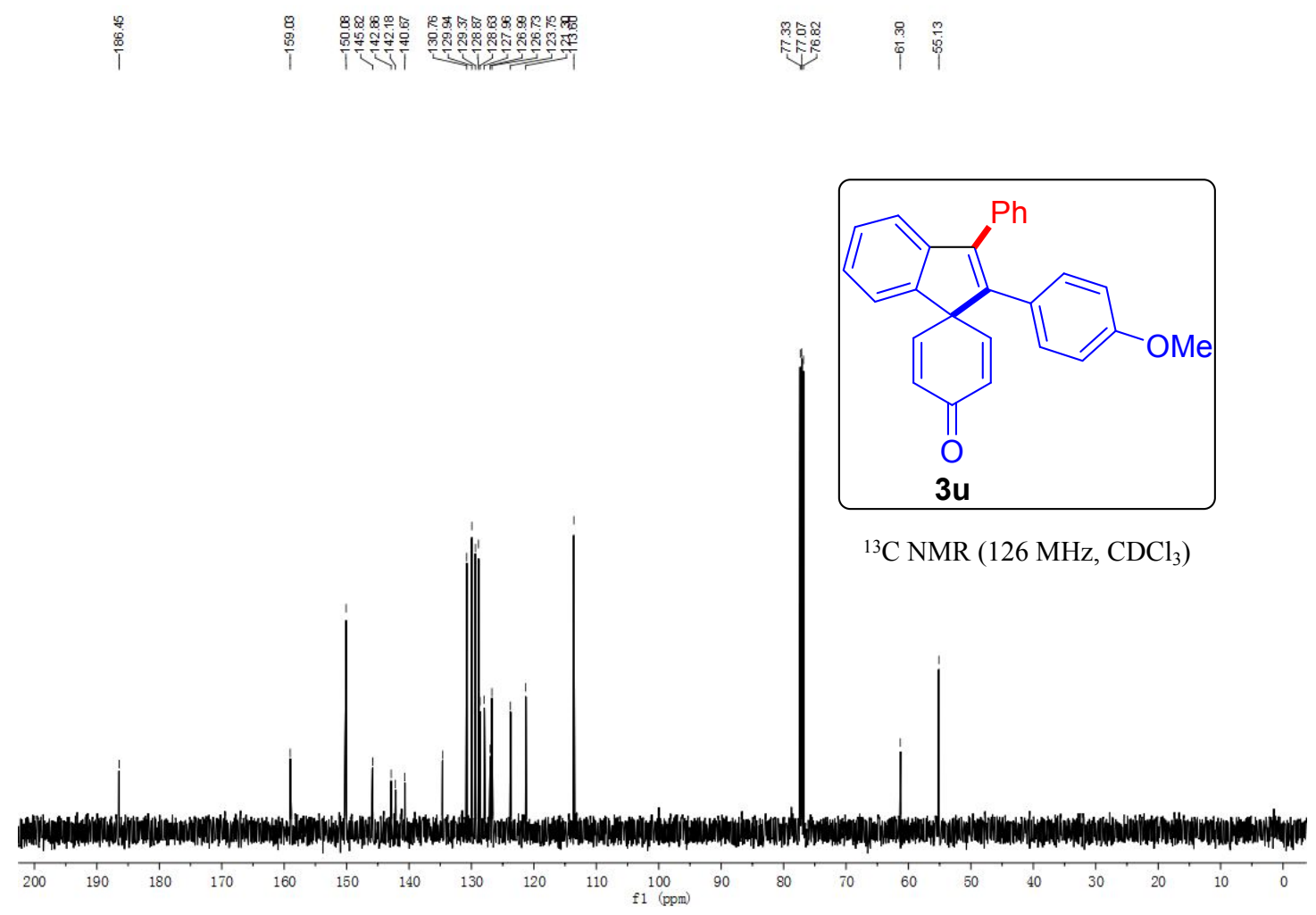

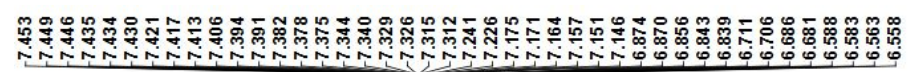

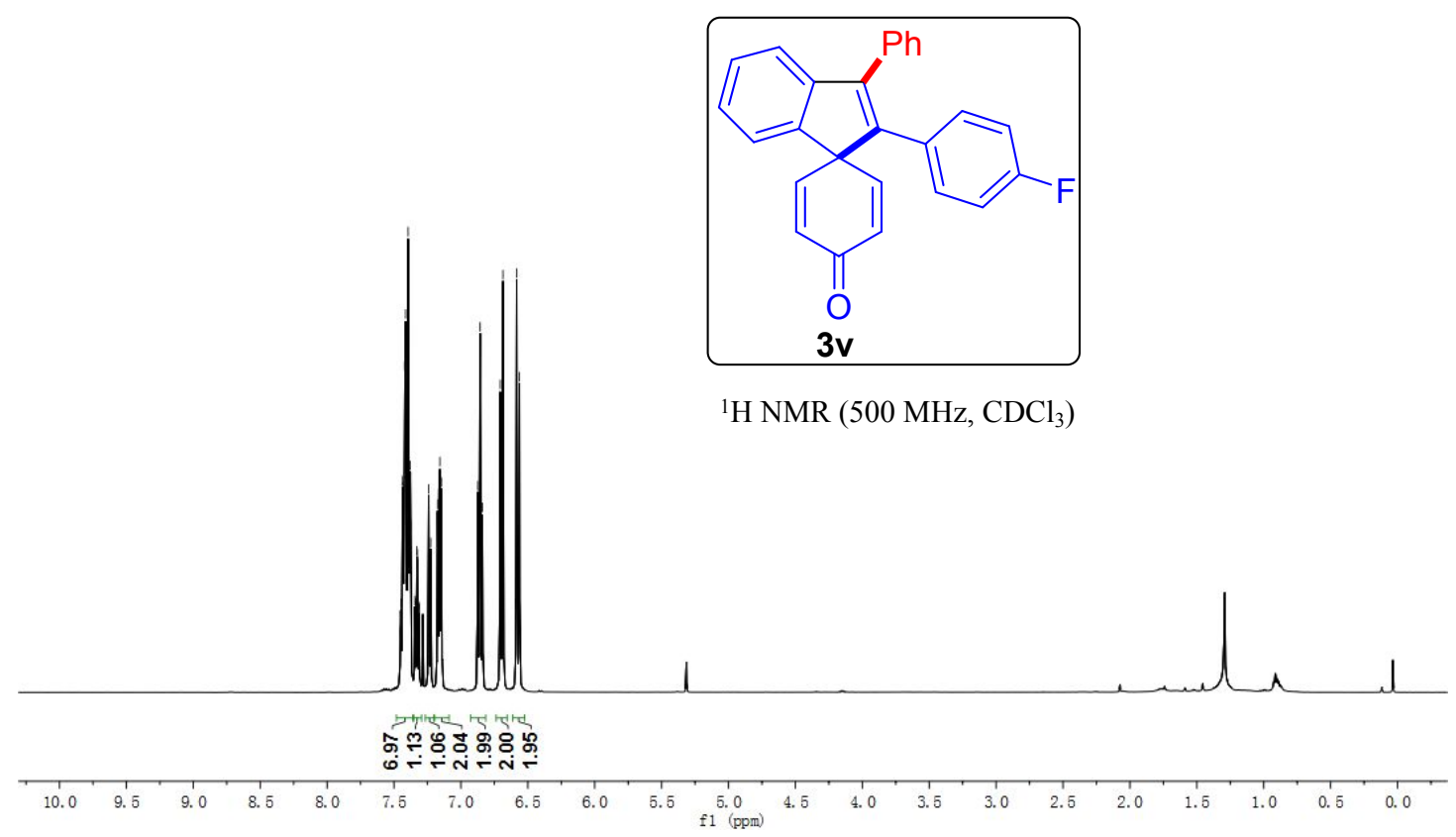




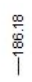

ำ

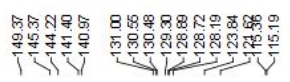

罂觉

$\frac{1}{4}$

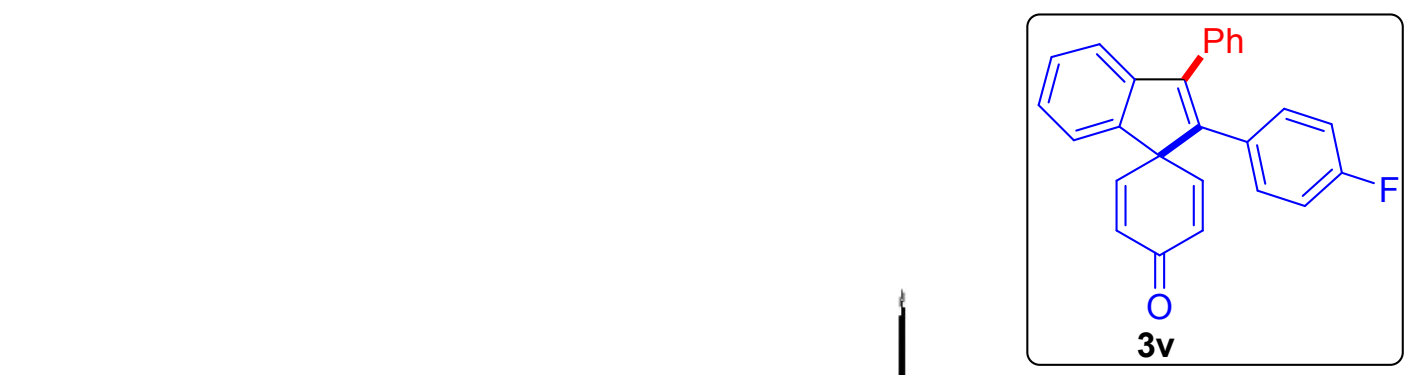

${ }^{13} \mathrm{C}$ NMR (126 MHz, $\mathrm{CDCl}_{3}$ )

3U-F
STAVARD FLUORINE PARALETERS

i

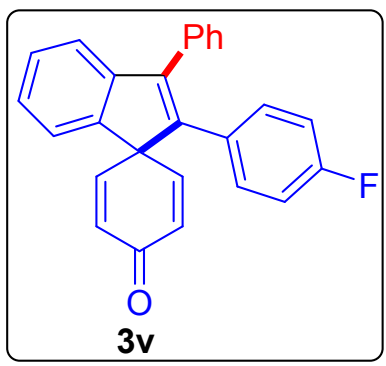

${ }^{19} \mathrm{~F}$ NMR (470 MHz, $\mathrm{CDCl}_{3}$ )

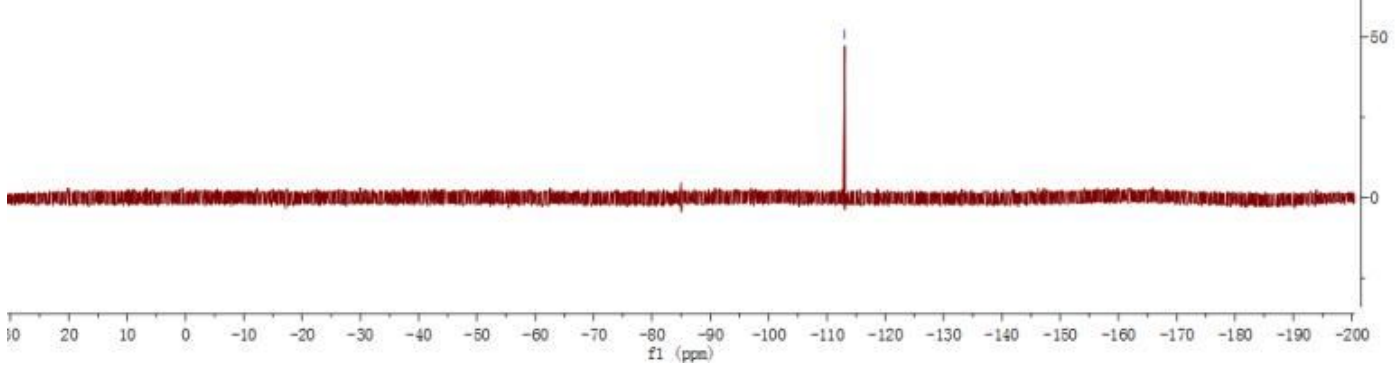

S23 


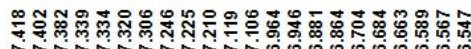

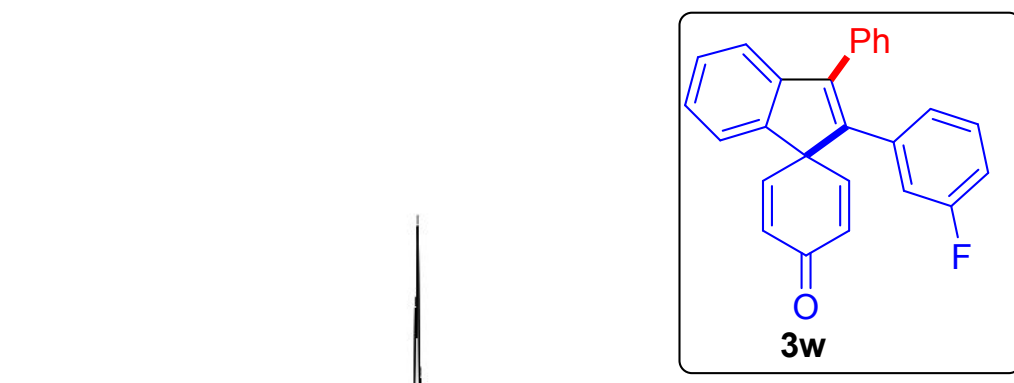

${ }^{1} \mathrm{H}$ NMR (500 MHz, $\mathrm{CDCl}_{3}$ )

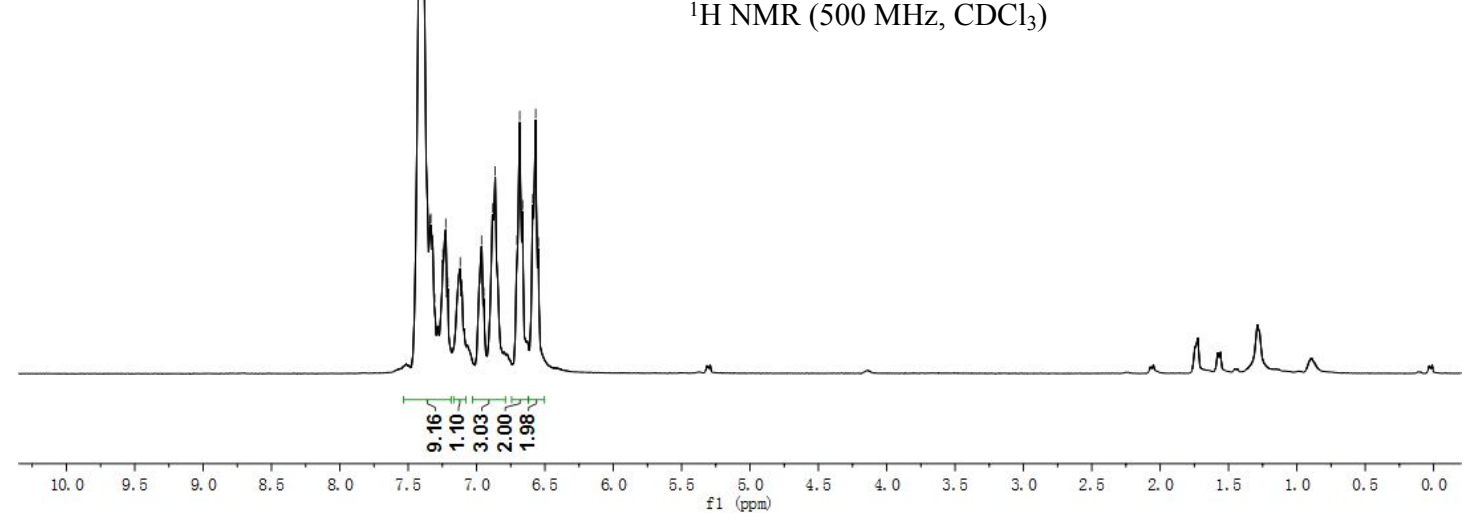

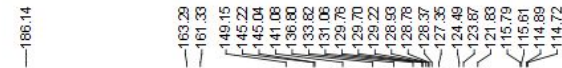

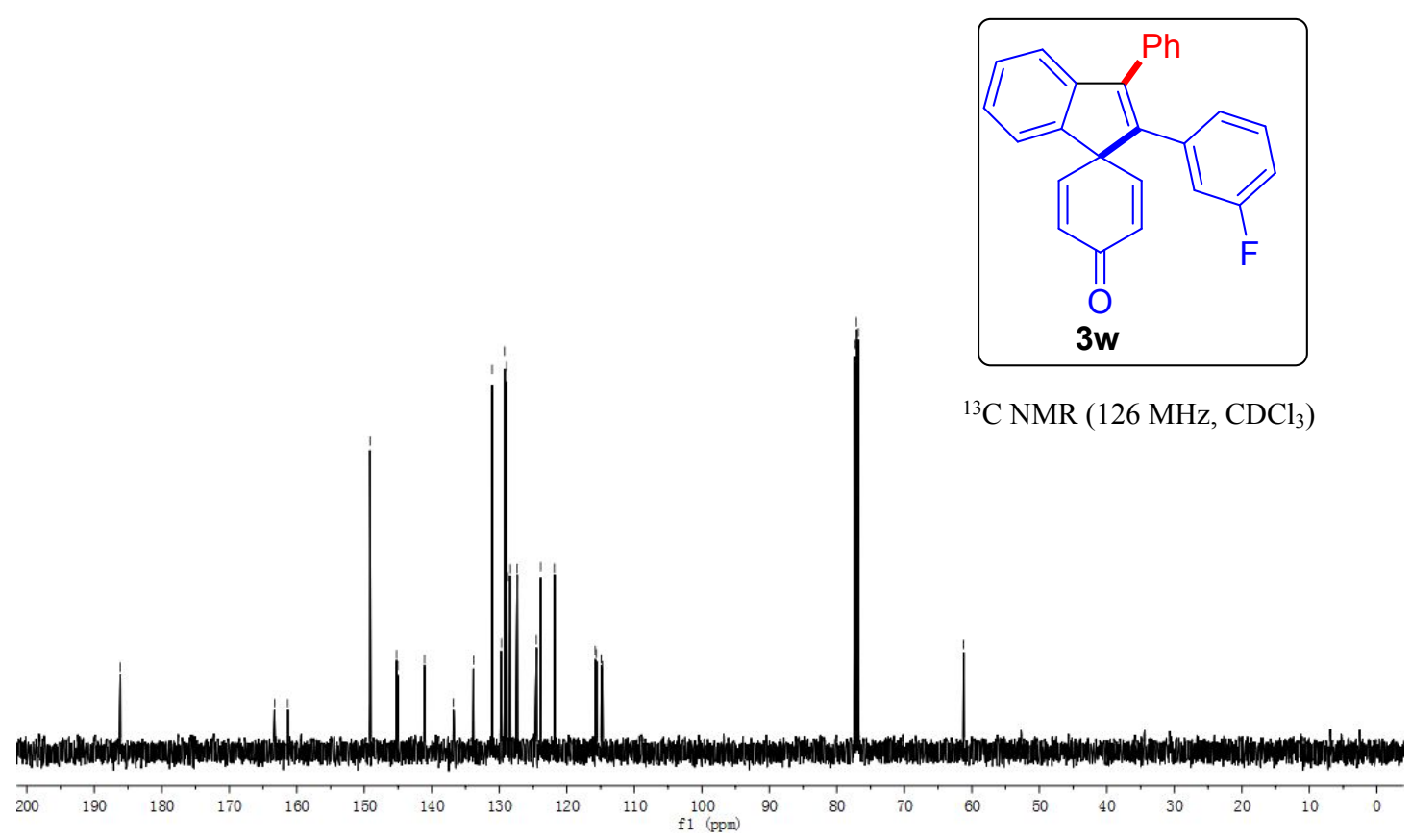




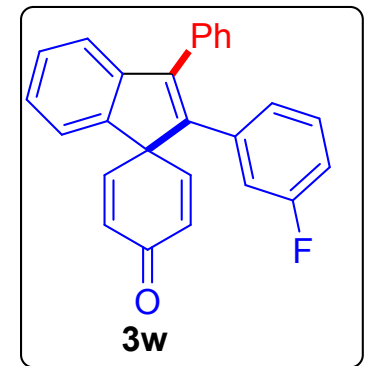

${ }^{19} \mathrm{~F}$ NMR $\left(470 \mathrm{MHz}, \mathrm{CDCl}_{3}\right)$

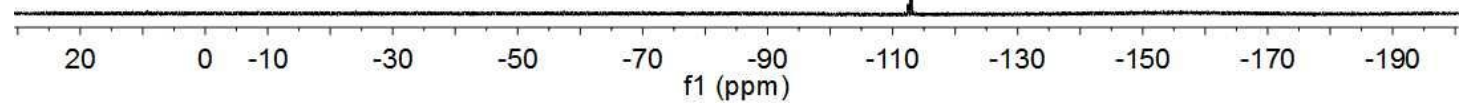

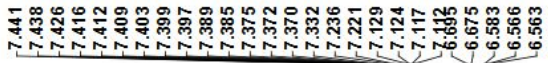

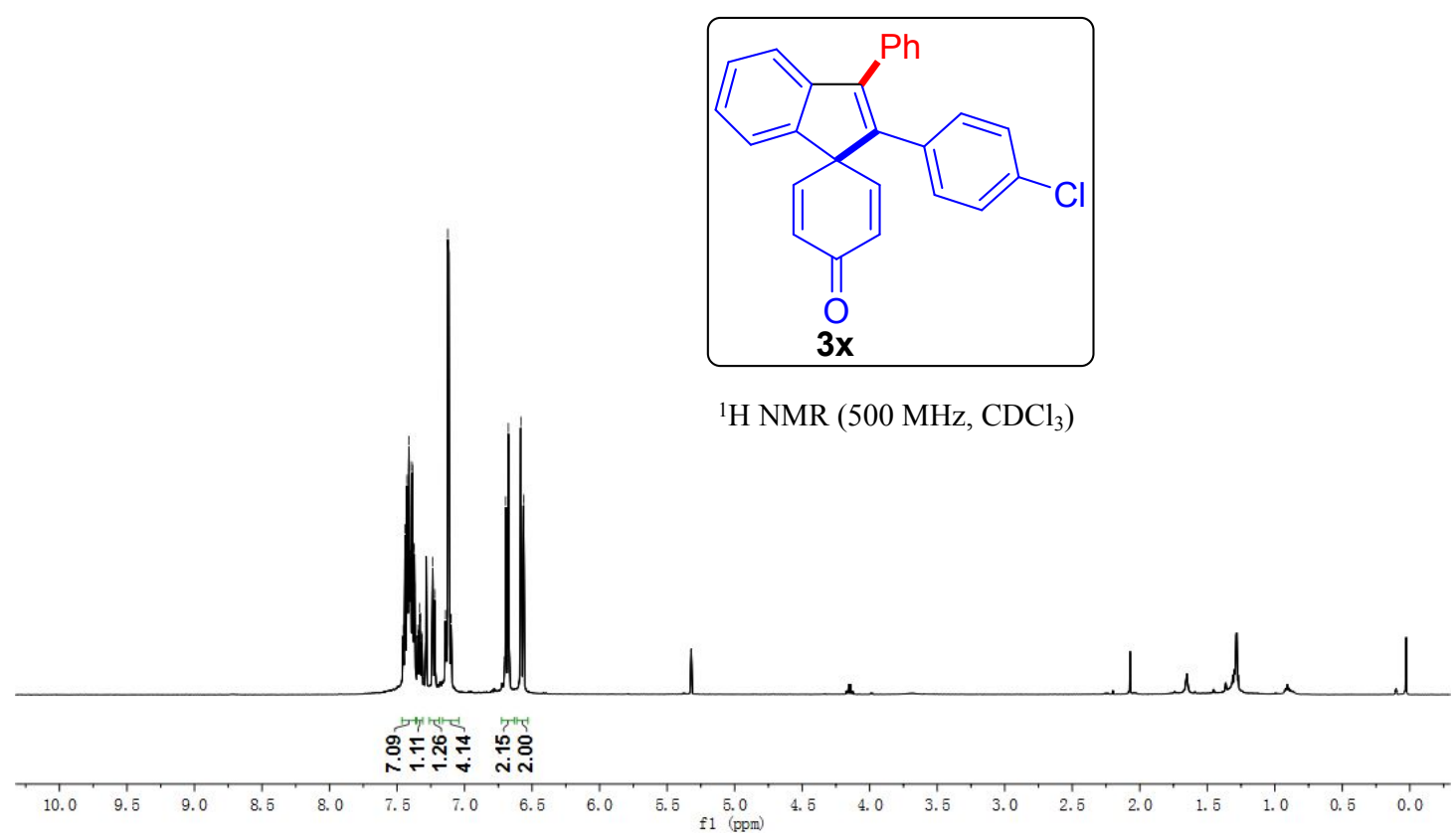




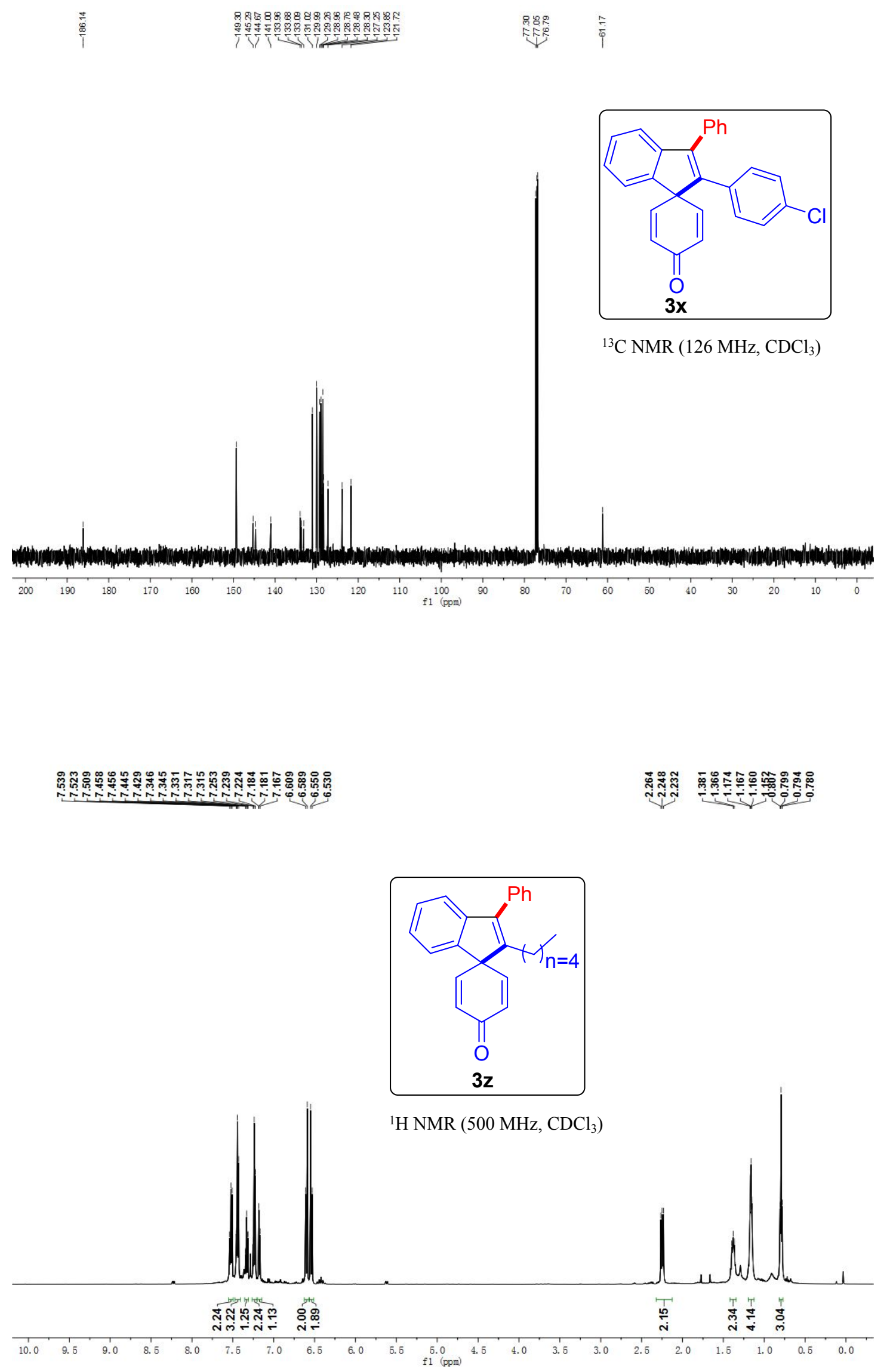




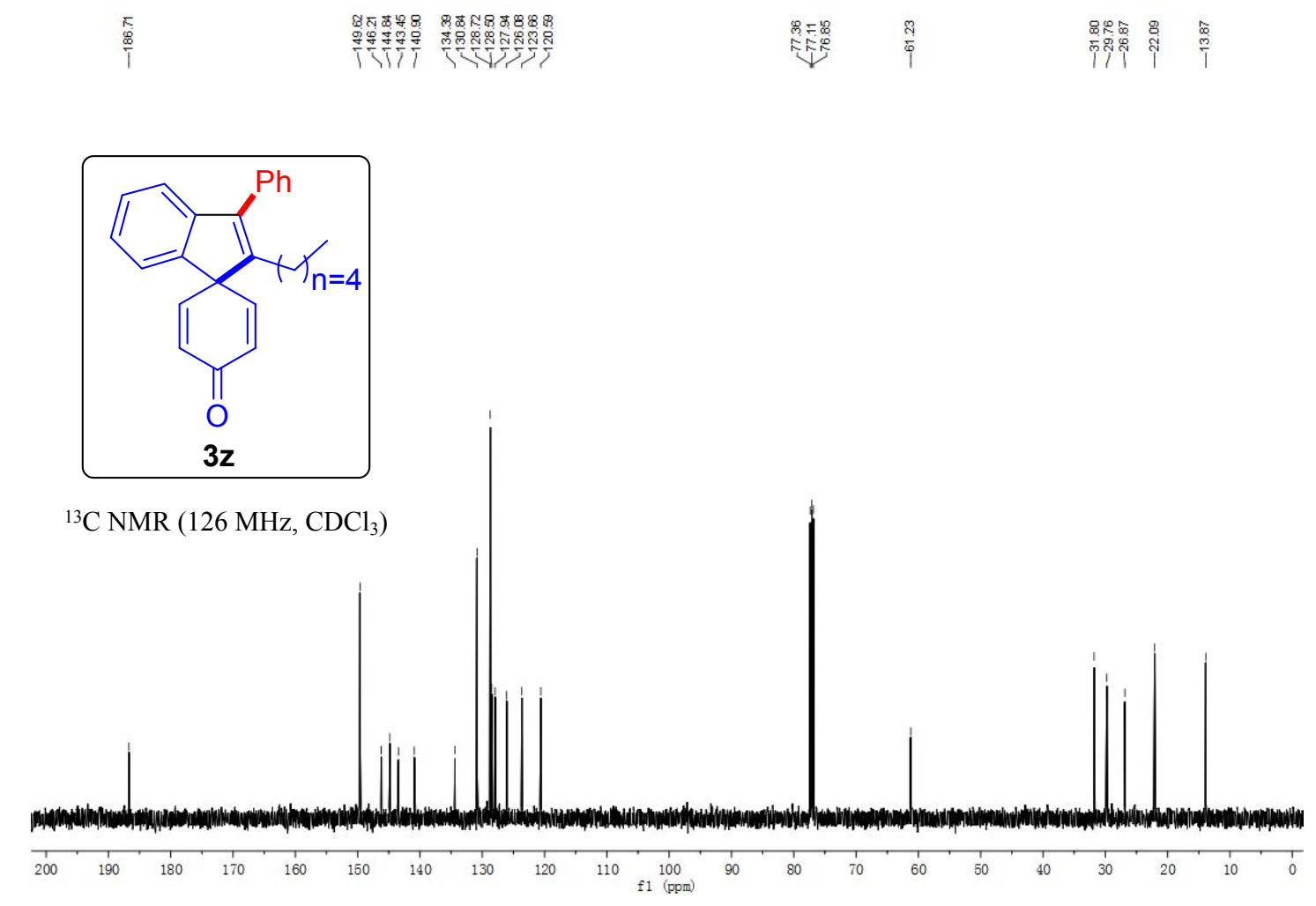


2. ${ }^{1} \mathrm{H},{ }^{13} \mathrm{C}$ and ${ }^{19}$ F NMR spectra (3a'-i')

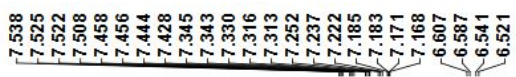

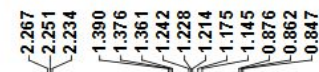
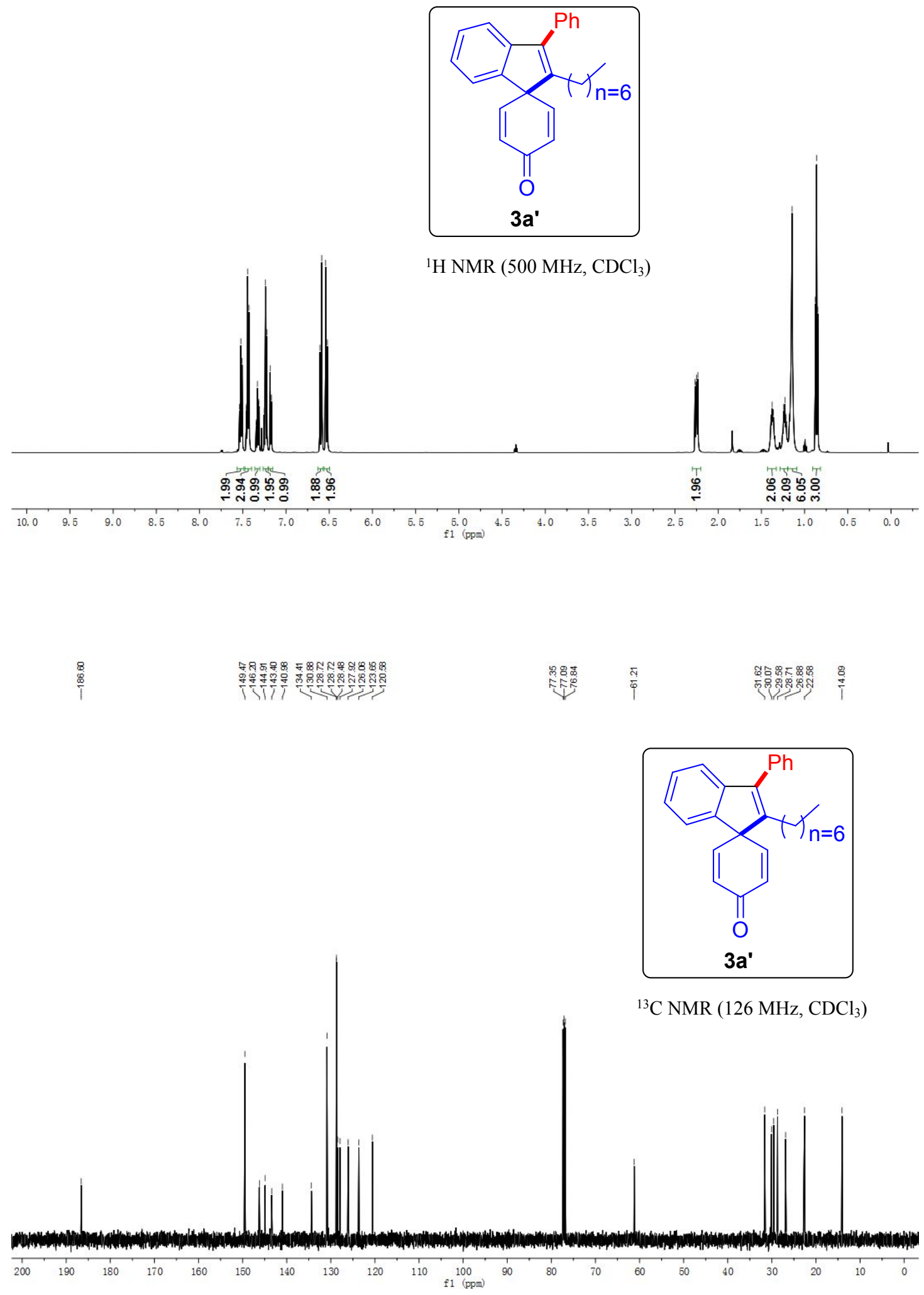


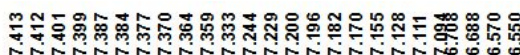

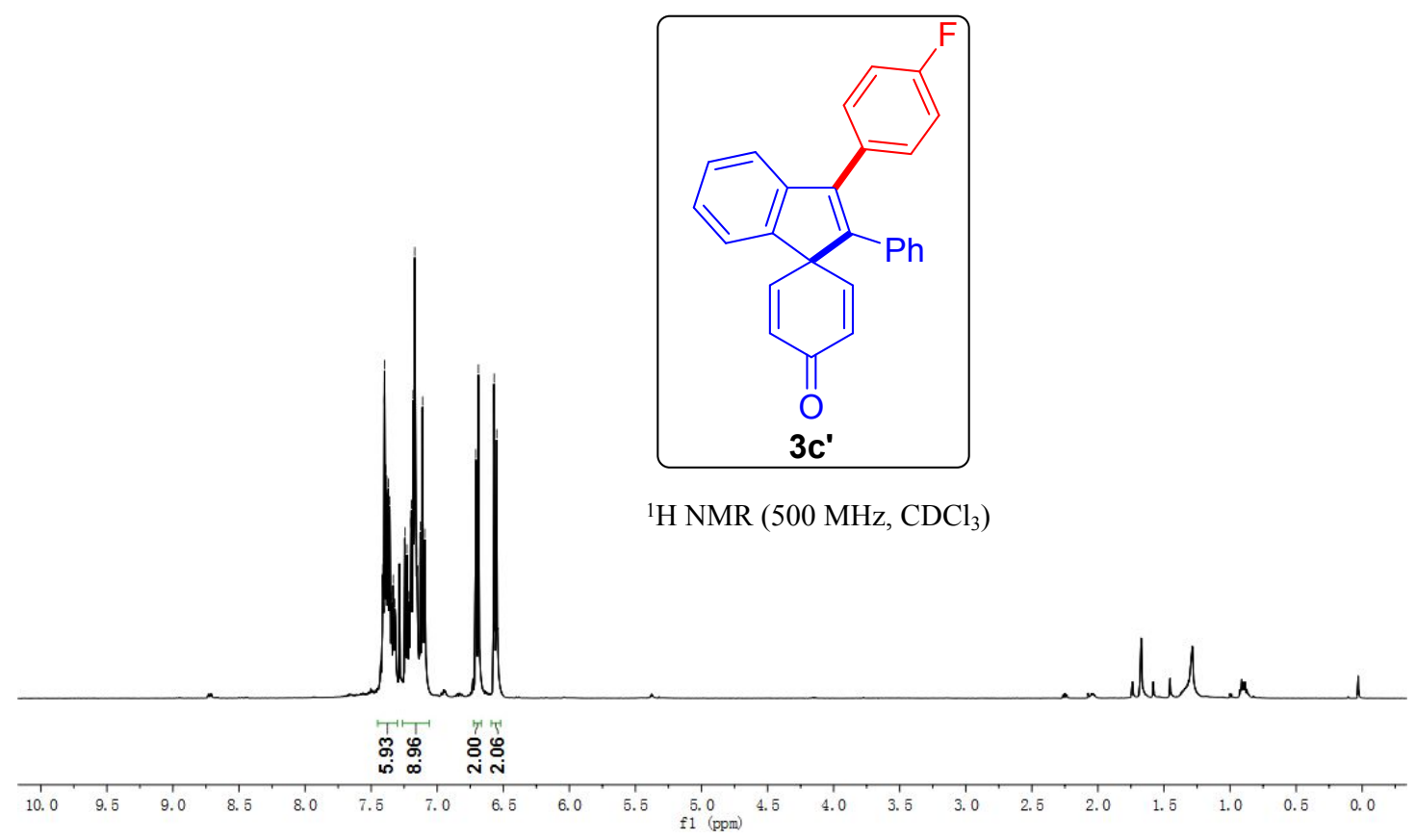

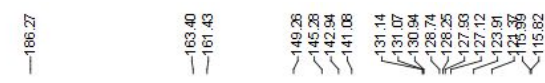

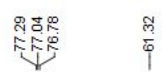

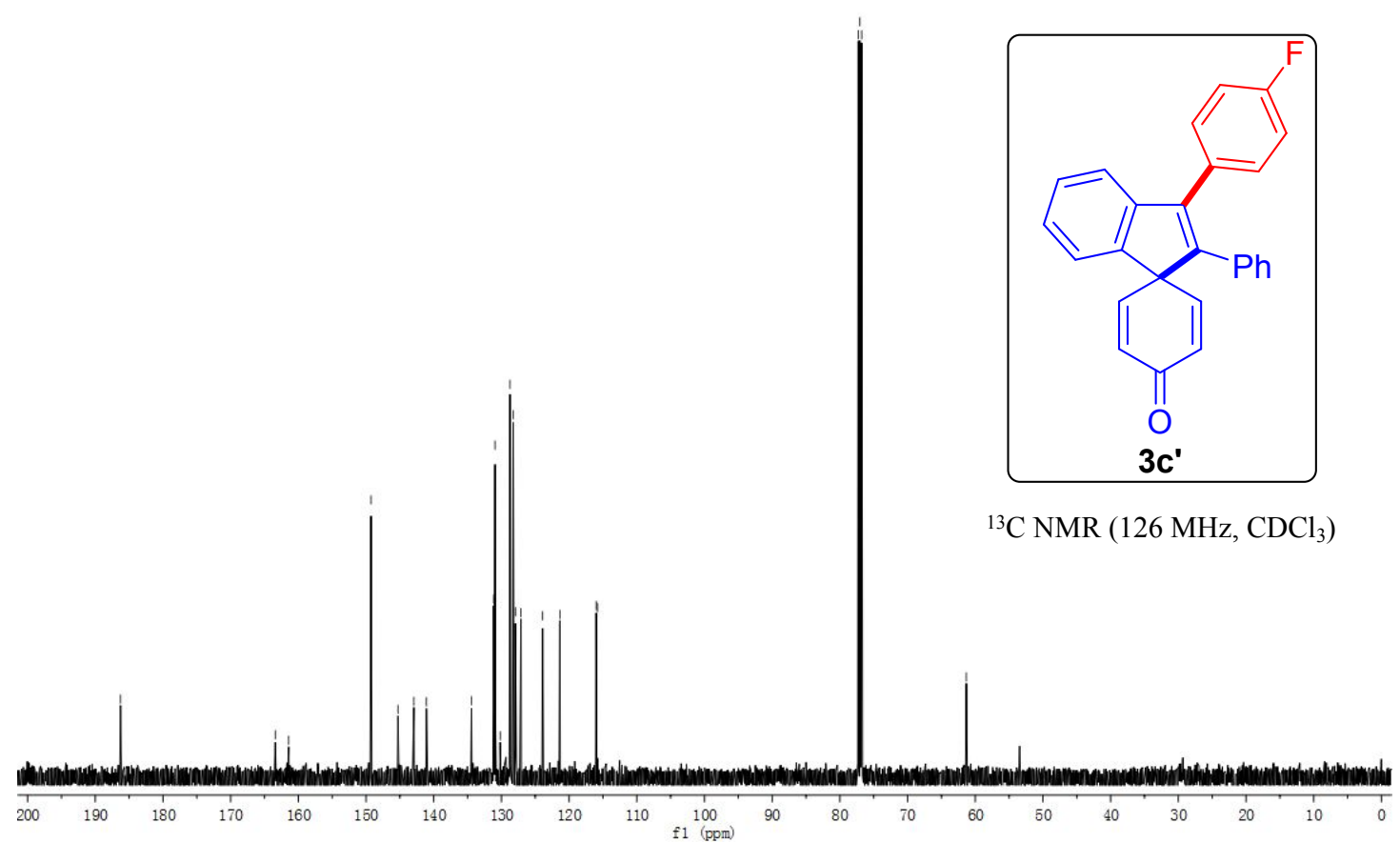


$3 e^{\prime}-F$
STANDARD FL UORINE PARALETERS

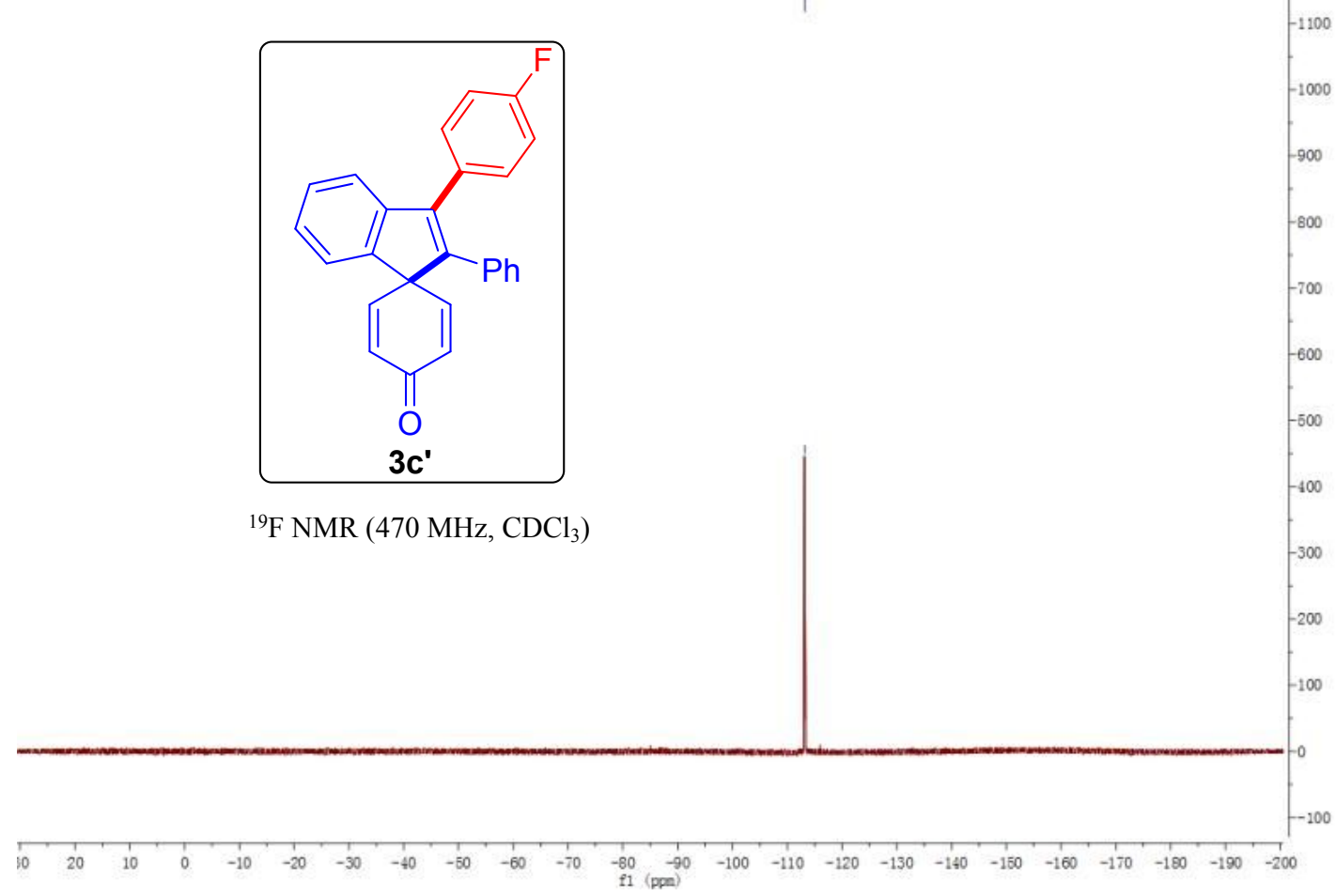

${ }^{19} \mathrm{~F}$ NMR (470 MHz, $\mathrm{CDCl}_{3}$ )

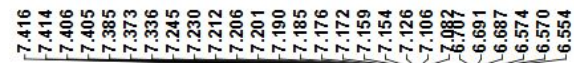

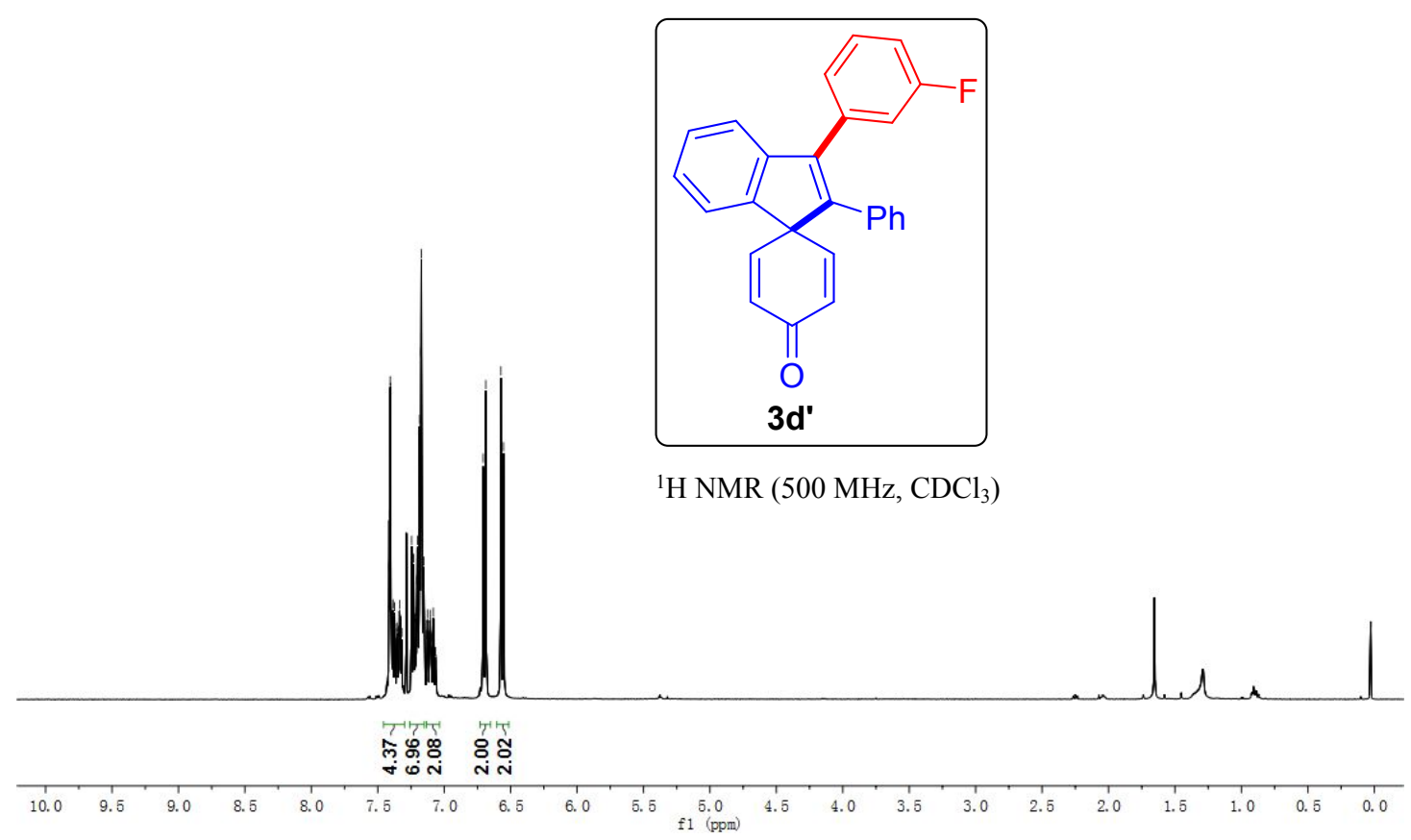




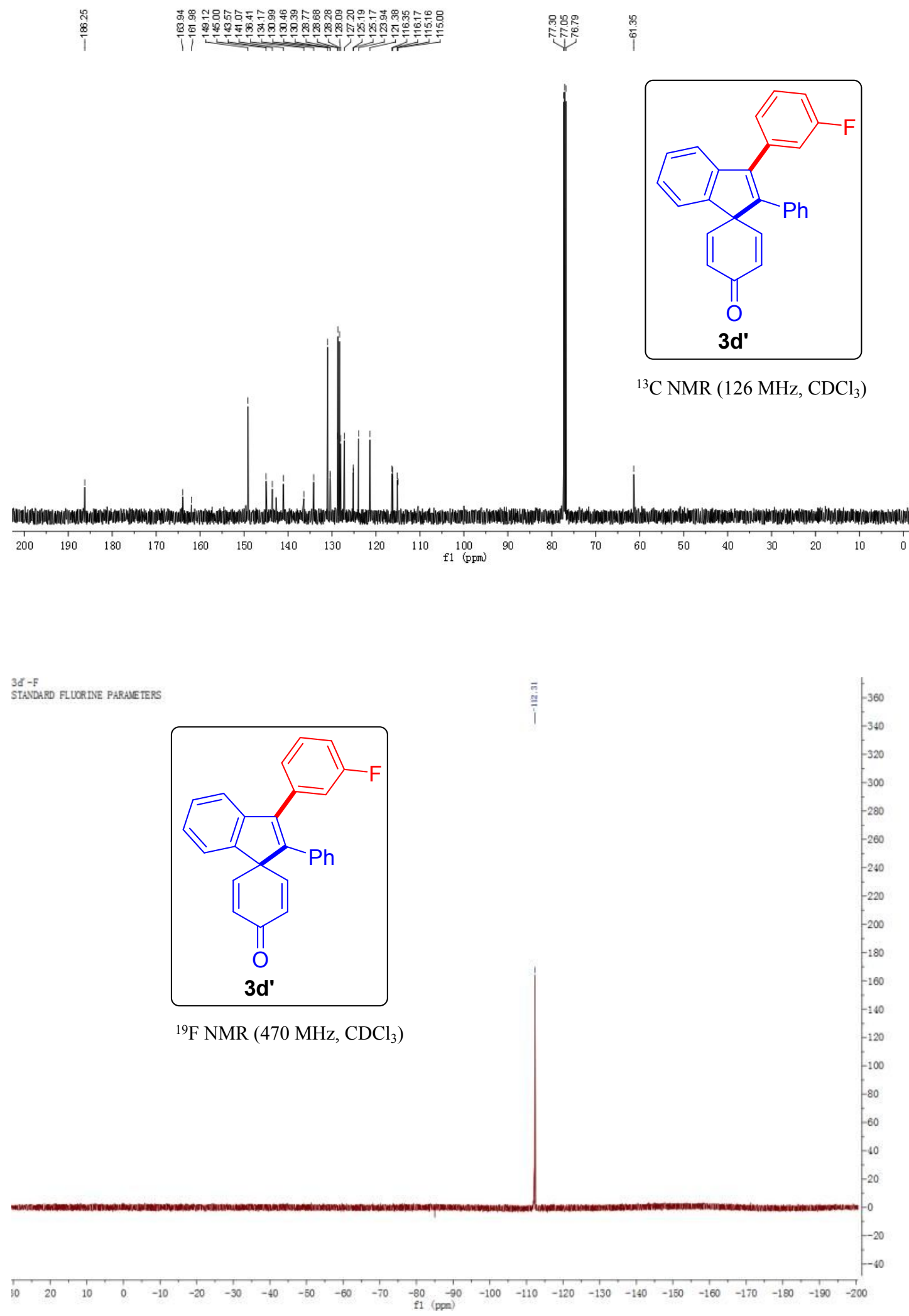




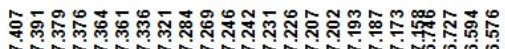

thesio

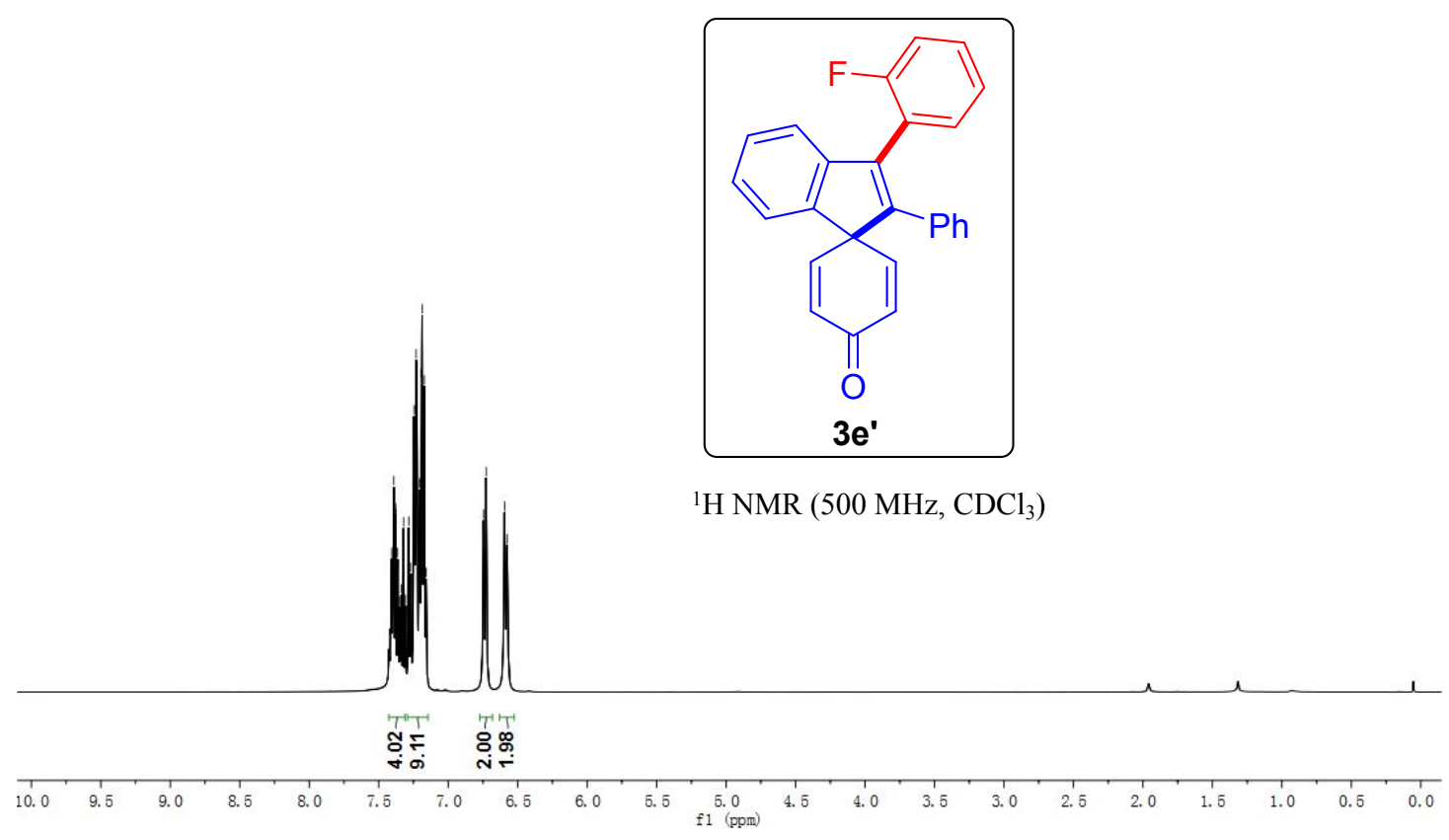

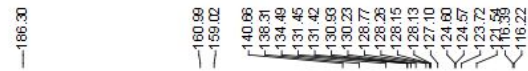

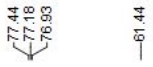

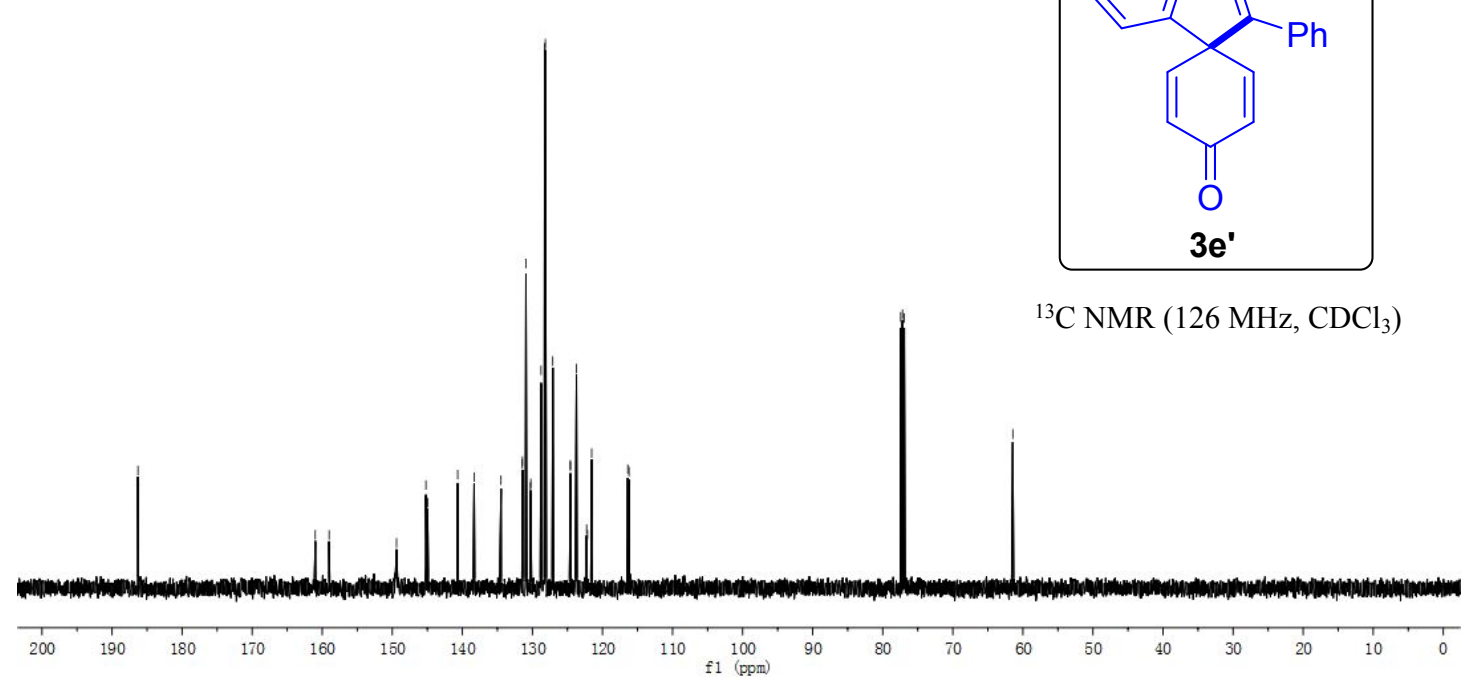




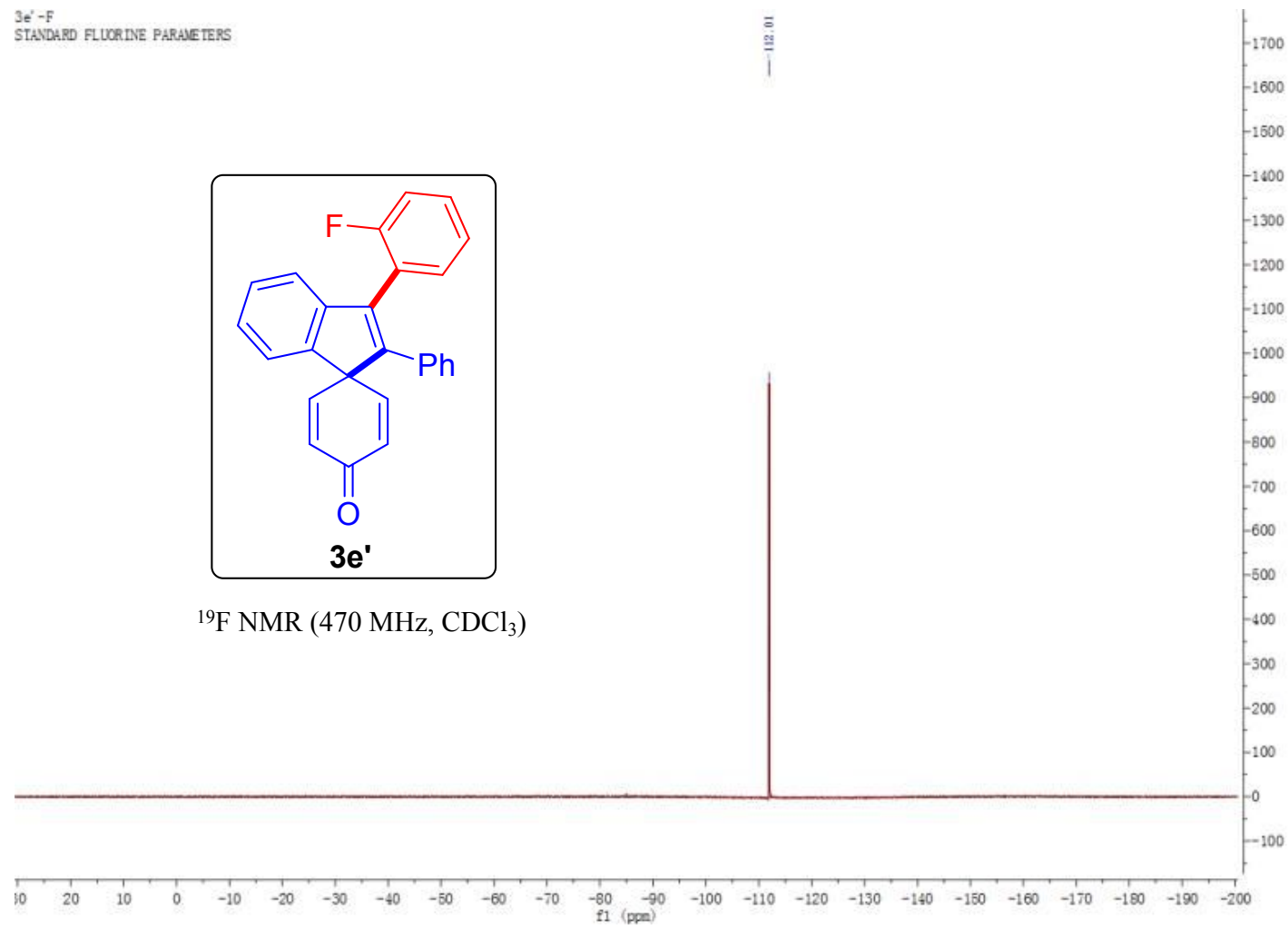

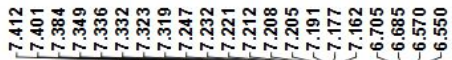

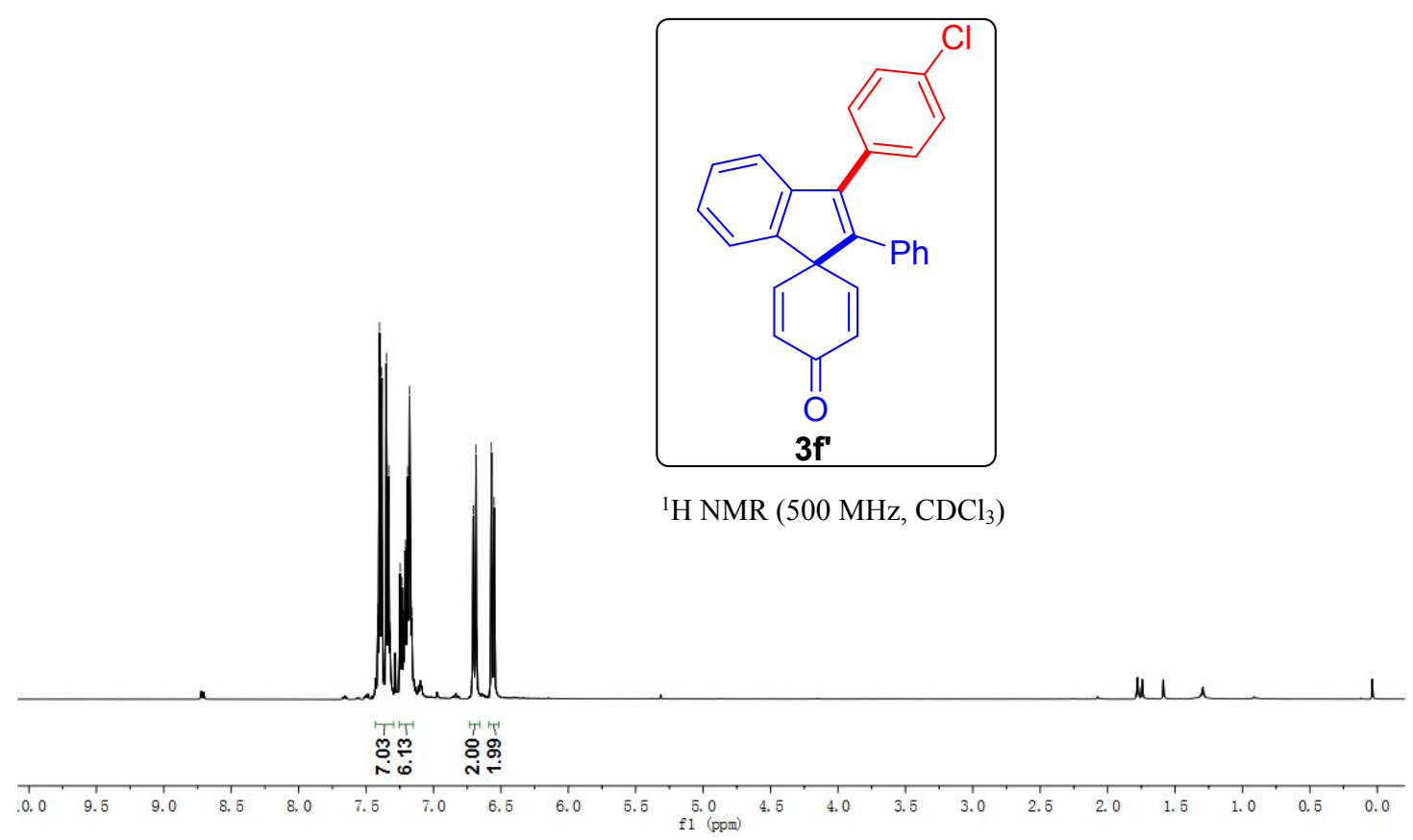




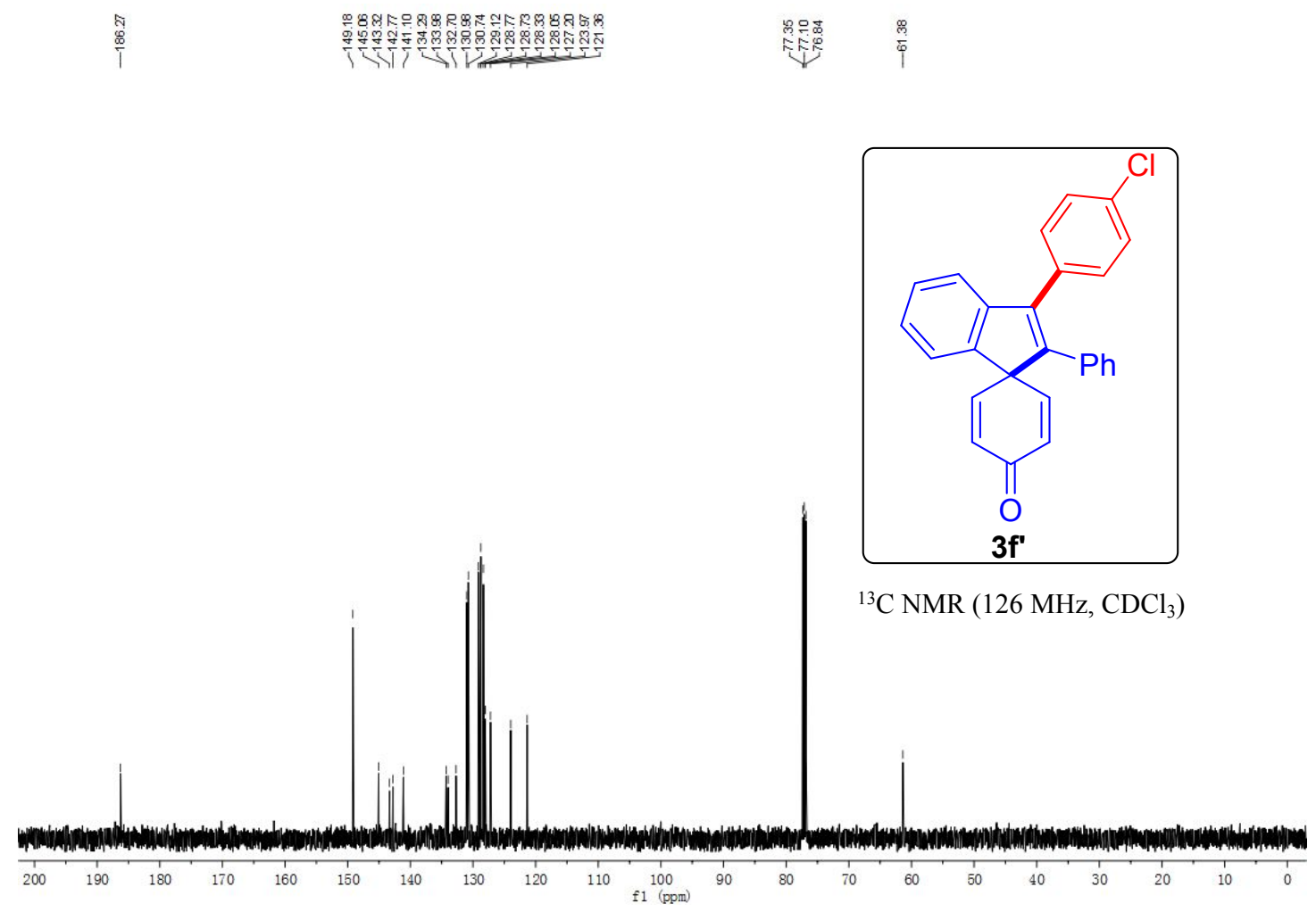

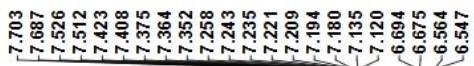

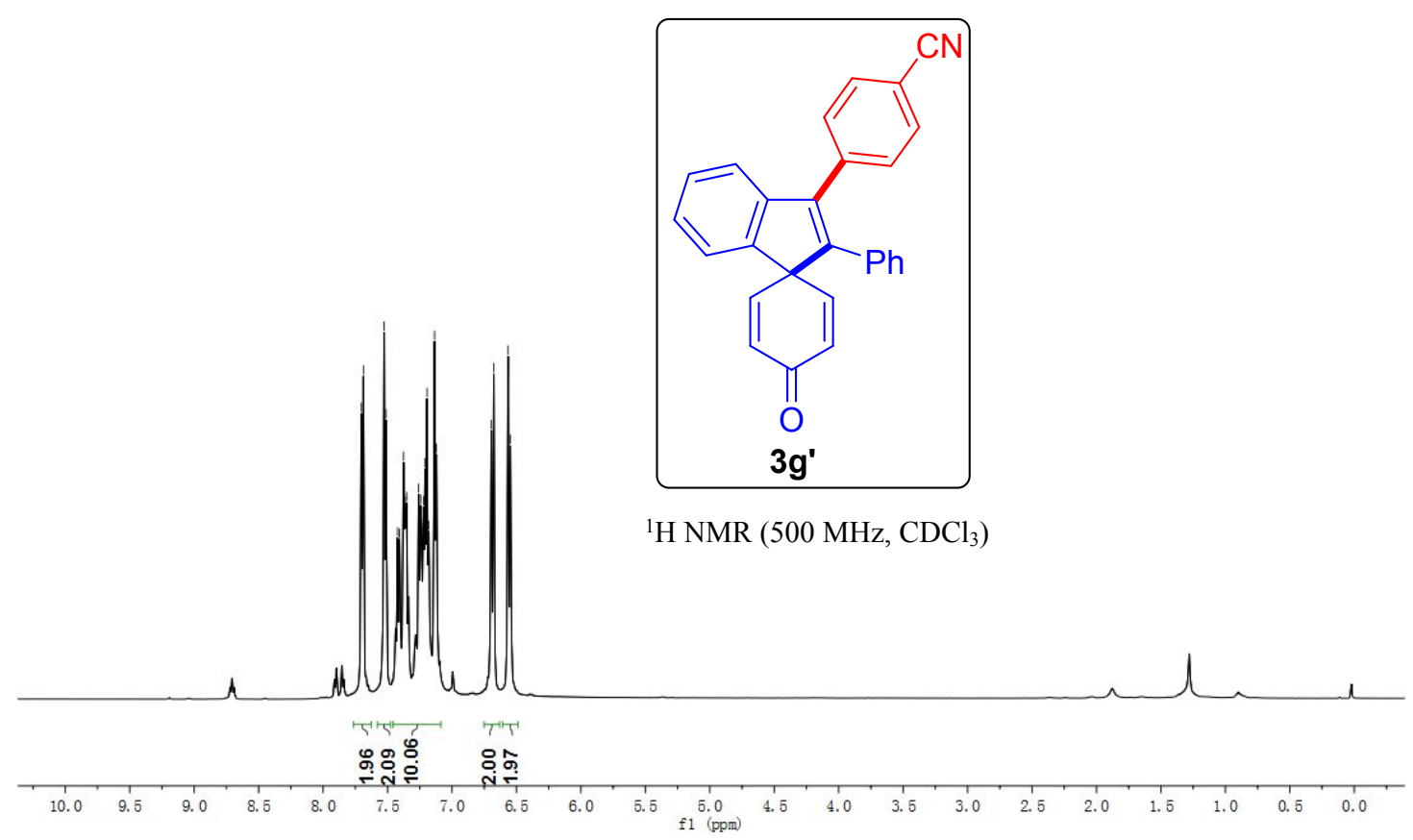




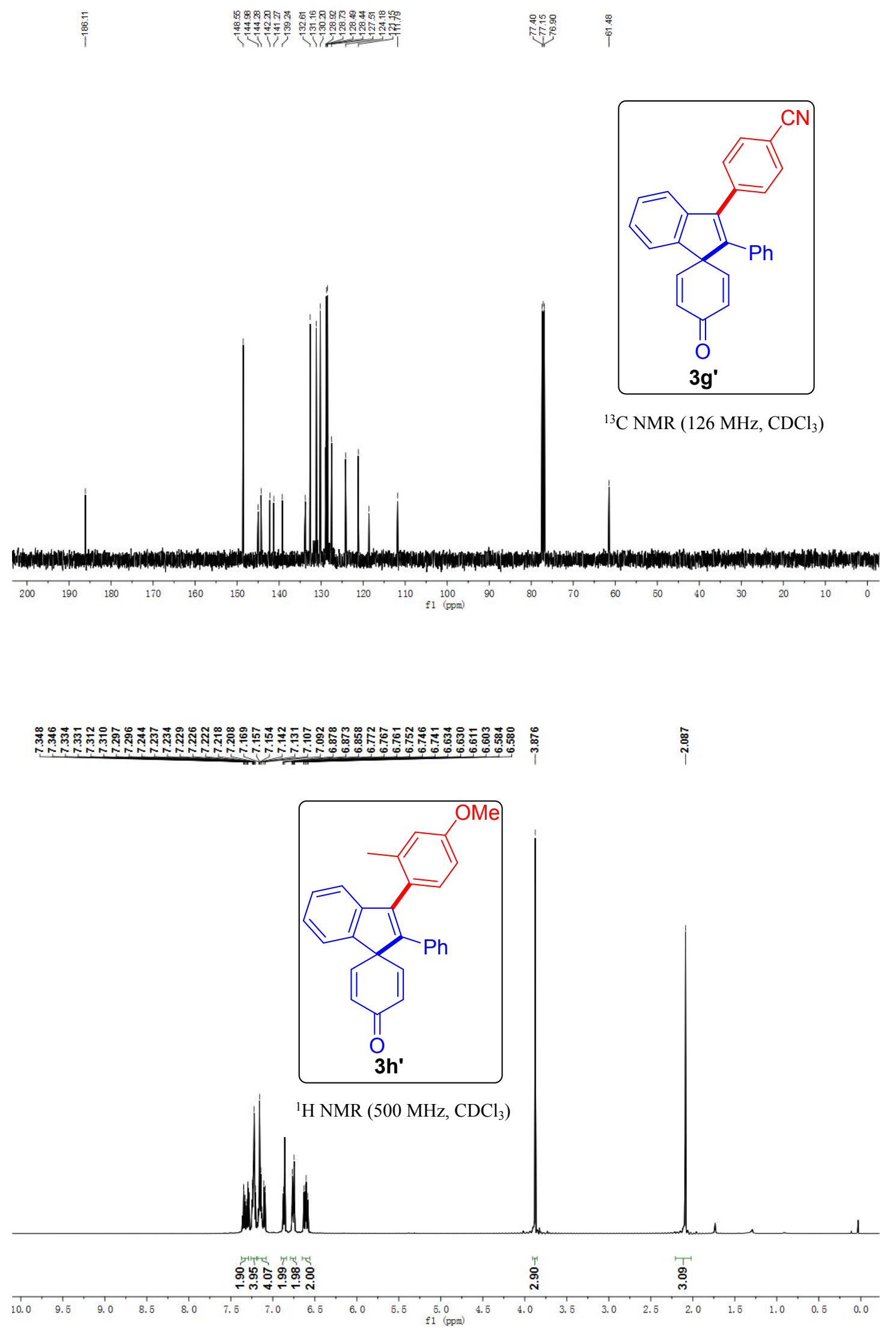



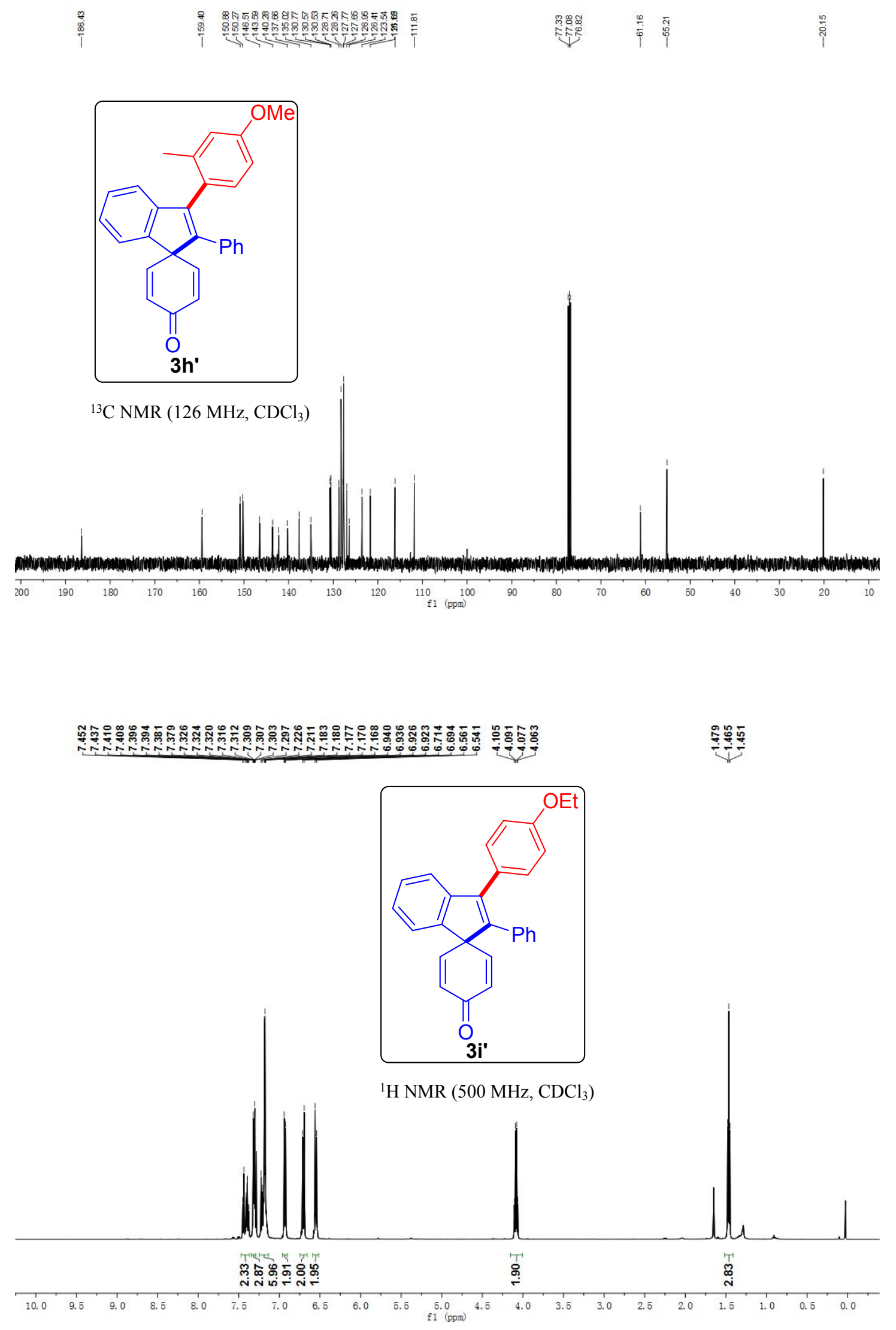


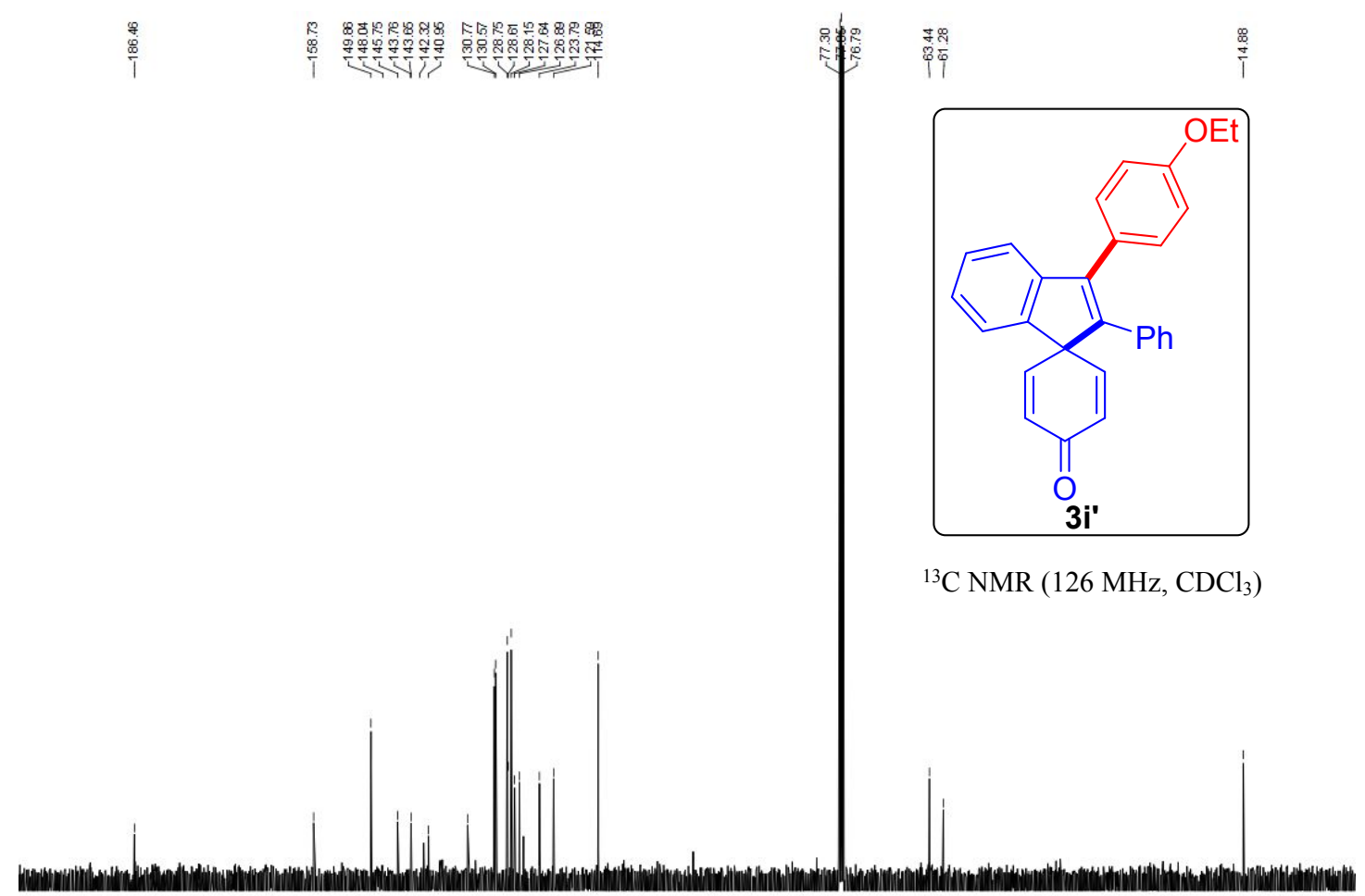

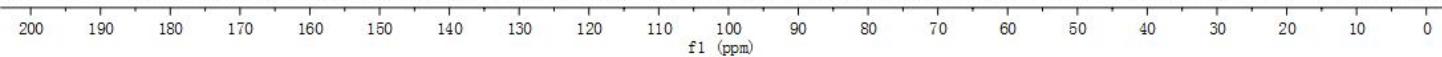

